\title{
THE FUNCTIONAL ROLE OF CHONDROGENIC STEM/PROGENITOR CELLS: NOVEL EVIDENCE FOR IMMUNOMODULATORY PROPERTIES AND REGENERATIVE POTENTIAL AFTER CARTILAGE INJURY
}

\author{
J. Riegger ${ }^{1}$, H.G. Palm ${ }^{2}$ and R.E. Brenner ${ }^{1, *}$ \\ ${ }^{1}$ Division for Biochemistry of Joint and Connective Tissue Diseases, Department of Orthopaedics, \\ University of Ulm, Ulm, Germany \\ ${ }^{2}$ Department of Orthopaedics and Trauma Surgery, German Armed Forces Hospital Ulm, Ulm, Germany
}

\begin{abstract}
Considering the poor intrinsic healing potential of articular cartilage, resident chondrogenic stem/progenitor cells (CSPCs) have gained attention in recent years. Although, CSPCs are attracted by a cartilage injury, knowledge about the post-traumatic behaviour and functional role of this cell population is fairly basic. The present study, not only elaborated on the regenerative capacities of CSPCs, but also illuminated potential immunomodulatory properties after cartilage trauma.

Estimation of the CSPC population size within previously impacted cartilage explants by flow-cytometry revealed an increased percentage of CSPC-marker positive cells as compared to unimpacted tissue. In line with this, proliferation, chemotactic migration and in vitro wound healing activity of isolated CSPCs was similarly enhanced after stimulation with trauma-conditioned (TC) medium. Further, a significant increase in pro- and anti-inflammatory gene expression, as well as IL-6 secretion due to TC-medium-stimulation was measured. In this context, antioxidative or chondroanabolic therapeutic intervention alleviated the post-traumatic response of TC-medium-activated CSPCs and substantially influenced CSPC chondrogenic differentiation in different ways.

Overall, this study provided novel insights into the functional role of CSPCs after cartilage trauma and the effects of a therapeutic intervention in order to improve regenerative processes and prevent cartilage degeneration following trauma.
\end{abstract}

Keywords: Chondrogenic stem/progenitor cells, cartilage trauma, post-traumatic osteoarthritis, damageassociated molecular patterns, immunomodulation, chondrogenic differentiation, fibroblast growth factor 18, bone morphogenetic protein 7 , insulin-like growth factor $1, \mathrm{~N}$-acetyl cysteine.

*Address for correspondence: R.E. Brenner, Oberer Eselsberg 45, 89081, Ulm, Germany. Telephone number: +49 73150063280Ｅmail: rolf.brenner@uni-ulm.de

Copyright policy: This article is distributed in accordance with Creative Commons Attribution Licence (http://creativecommons.org/licenses/by-sa/4.0/).

\begin{tabular}{|c|c|c|c|}
\hline & List of abbreviations & $\begin{array}{l}\text { DMEM } \\
\text { ECM }\end{array}$ & $\begin{array}{l}\text { Dulbecco's modified Eagle medium } \\
\text { extracellular matrix }\end{array}$ \\
\hline ADAM8 & $\begin{array}{l}\text { a disintegrin and metalloproteinase } \\
8\end{array}$ & ELISA & $\begin{array}{l}\text { enzyme-linked immunosorbent } \\
\text { assay }\end{array}$ \\
\hline BM-MSCs & $\begin{array}{l}\text { bone-marrow-derived mesenchymal } \\
\text { stromal/stem cells }\end{array}$ & $\begin{array}{l}\mathrm{FADH}_{2} \\
\mathrm{FCS}\end{array}$ & $\begin{array}{l}\text { reduced flavin adenine dinucleotide } \\
\text { foetal calf serum }\end{array}$ \\
\hline BMP7 & bone morphogenetic protein 7 & FGF18 & fibroblast growth factor 18 \\
\hline $\mathrm{CC}$ & cartilage-conditioned & $\mathrm{FMNH}_{2}$ & reduced flavin mononucleotide \\
\hline CDM & $\begin{array}{l}\text { chondrogenic differentiation } \\
\text { medium }\end{array}$ & $\begin{array}{l}\text { Fn-fs } \\
\text { HMGB1 }\end{array}$ & $\begin{array}{l}\text { fibronectin fragments } \\
\text { high-mobility group box } 1\end{array}$ \\
\hline COMP & cartilage oligomeric matrix protein & IGF-1 & insulin-like growth factor 1 \\
\hline CSPCs & chondrogenic stem/progenitor cells & IHC & immunohistochemistry \\
\hline CXCL1 & chemokine (C-X-C motif) ligand 1 & IL & interleukin \\
\hline DAMPs & $\begin{array}{l}\text { damage-associated molecular } \\
\text { patterns }\end{array}$ & $\begin{array}{l}\text { ITS } \\
\text { NAC }\end{array}$ & $\begin{array}{l}\text { insulin-transferrin-sodium selenite } \\
\mathrm{N} \text {-acetyl cysteine }\end{array}$ \\
\hline
\end{tabular}




\begin{tabular}{|c|c|}
\hline NADH & reduced nadide \\
\hline NADPH & $\begin{array}{l}\text { nicotinamide adenine dinucleotide } \\
\text { phosphate }\end{array}$ \\
\hline MSCA-1 & mesenchymal stromal cell antigen- 1 \\
\hline $\mathrm{OA}$ & osteoarthritis \\
\hline PBS & phosphate-buffered saline \\
\hline PDGF & platelet-derived growth factor \\
\hline PRG4 & lubricin \\
\hline PRRs & pattern recognition receptors \\
\hline PTOA & post-traumatic osteoarthritis \\
\hline RAGE & $\begin{array}{l}\text { receptor for advanced glycation end } \\
\text { products }\end{array}$ \\
\hline rh & recombinant human \\
\hline ROS & reactive oxygen species \\
\hline SDF-1 & stromal-derived factor- 1 \\
\hline SEM & standard error of the mean \\
\hline STAT3 & $\begin{array}{l}\text { signal transducer and activator of } \\
\text { transcription } 3\end{array}$ \\
\hline TBC & $\begin{array}{l}\text { medium obtained from impacted } \\
\text { cartilage explants treated } \\
\text { with BMP7 }\end{array}$ \\
\hline $\mathrm{TC}$ & trauma-conditioned \\
\hline TFC & $\begin{array}{l}\text { medium obtained from impacted } \\
\text { cartilage explants treated } \\
\text { with FGF18 }\end{array}$ \\
\hline TGF- $\beta 3$ & transforming growth factor beta-3 \\
\hline TIC & $\begin{array}{l}\text { medium obtained from impacted } \\
\text { cartilage explants treated with IGF1 }\end{array}$ \\
\hline TLR4 & toll-like receptor 4 \\
\hline TNC & $\begin{array}{l}\text { medium obtained from impacted } \\
\text { cartilage explants treated with NAC }\end{array}$ \\
\hline TNF- $\alpha$ & tumour necrosis factor $\alpha$ \\
\hline TSG6 & TNF-stimulated gene 6 protein \\
\hline VCAM1 & vascular cell adhesion molecule 1 \\
\hline
\end{tabular}

\section{Introduction}

Articular cartilage is an avascular tissue with little healing capacity. Consequently, injuries of the cartilage or the adjacent soft tissue represent a crucial risk factor for progressive cartilage degeneration and development of a PTOA (Whittaker et al., 2015). Even a single traumatic impact can initiate a chain reaction of pathomechanisms, characterised by ongoing cell death and degradation of the ECM driven by cytokines and ROS (Henrotin et al., 2005). Considering the high prevalence of arthritic joint diseases and the inefficacy of current therapeutic options, novel approaches providing not only symptomatic relief, but also support of the intrinsic regeneration are needed. Besides pharmacologic treatment, cell-based therapy has increasingly gained importance. In this context, immunomodulatory properties of BM-MSCs and their possible application in arthritic diseases are described (van Buul et al., 2012). A migratory cartilage-resident cell population, also referred to as CSPCs, has gained attention due to its beneficial localisation and innate chondrogenic phenotype, reflected in superior chondrogenic differentiation capacities as compared to BM-MSCs
(Jiang and Tuan, 2015; Xue et al., 2016). Moreover, CSPCs possess multipotent differentiation capacities and a surface marker expression profile similar to that of BM-MSCs, including the minimal criteria, commonly used to identify MSCs (Dominici et al., 2006; Joos et al., 2013). This makes CSPCs a promising target to improve intrinsic healing of cartilage defects but also in terms of tissue engineering (Elsaesser et al., 2016; Jiang and Tuan, 2015).

CSPCs are attracted by DAMPs, such as HMGB1 (Seol et al., 2012), and signalling molecules, comprising SDF-1 (Yu et al., 2015), IGF-1 and PDGF (Joos et al., 2013). In contrast, OA-associated cytokines IL-1ß and TNF- $\alpha$ significantly inhibit the migration of CSPCs towards TC medium (Joos et al., 2013). CSPCs might also contribute to the clearance of cell and matrix debris, such as Fn-fs, which are generated after mechanical impact, and trigger detrimental chondrolysis (Ding et al., 2014; Zhou et al., 2016). Moreover, comprehensive microarray analysis of CSPCs reveals high expression levels of PRG4, a disease-modifying and surface-protective lubricant, implying further chondro-protective properties of the cell population (Flannery et al., 2009; Seol et al., 2012).

CSPCs express significantly higher levels of inflammation-associated genes, such as $I L-6$ and -8 , as compared to chondrocytes (Seol et al., 2012; Zhou et al., 2014), although CSPC-mediated contribution to the inflammatory response after trauma is not confirmed so far. Since DAMPs, in particular HMGB1 and S100A8/9, induce pro-inflammatory response by signalling through PRRs, namely TLR4 and RAGE (Bertheloot and Latz, 2017), the current study's working hypothesis was that DAMPs not only trigger chemotaxis but might also elicit an immunomodulatory response in CSPCs. To elucidate this issue, isolated CSPCs were stimulated with culture medium obtained from impacted cartilage explants and the expression of relevant key mediators involved in immunomodulation was evaluated. Moreover, classic in vitro wound healing, proliferation, chemotaxis and chondrogenic differentiation assays were included to examine the impact of trauma-related factors on CSPC regenerative capacities.

As a second objective, the study extended its focus from the post-traumatic role and behaviour of CSPCs to the possibility of influencing this response by using antioxidative and chondroanabolic therapeutics, such as NAC (Riegger et al., 2016), FGF18, BMP7 and IGF-1 (Riegger et al., 2017).

\section{Materials and Methods}

\section{Preparation and cultivation of human cartilage explants}

Human cartilage was obtained from donors undergoing total knee joint replacement due to OA. Informed consent was obtained from all patients 
Table 1. Composition of the single panels and fluorescent labelling of the antibodies. Fluorescein isothiocyanate (FITC), phycoerythrin (PE), peridinin-chlorophyll protein (PerCP), allophycocyanin (APC). Antibodies labelled with Alexa Fluor 647 are indicated by an asterisk.

\begin{tabular}{|c|c|c|c|c|}
\hline Panel & FITC & PE & PerCP & APC/Alexa Fluor $647^{*}$ \\
\hline A & CD90 (Thy-1) & CD166 (ALCAM) & CD45 & Stro-1* \\
\hline Iso A & $\operatorname{IgG1\kappa }$ & $\operatorname{IgG1\kappa }$ & IgG1 & $\operatorname{IgM} \lambda$ * \\
\hline B & CD105 (endoglin) & CD73 & CD9 & MSCA-1 \\
\hline Iso B & $\operatorname{IgG} 2 \mathrm{a}$ & $\operatorname{IgG1\kappa }$ & IgG1 & $\operatorname{IgG1\kappa }$ \\
\hline
\end{tabular}

according to the terms of the ethics committee of the University of Ulm, Germany. Only macroscopically intact tissue samples (International Cartilage Repair Society score $\leq 1$ ) (Kleemann et al., 2005) from femoral condyles were included in the study. Full-thickness cartilage explants (6 $\mathrm{mm}$ in diameter) were cultivated in serum-containing chondrocyte medium $[1: 1$ DMEM/Ham's F12, $10 \%$ foetal bovine serum, $0.5 \%$ penicillin/streptomycin (PAA Laboratories), $0.5 \%$ L-glutamine and $10 \mu \mathrm{g} / \mathrm{mL}$ 2-phospho-L-ascorbic acid trisodium salt (Sigma-Aldrich)] at $37^{\circ} \mathrm{C}, 5 \% \mathrm{CO}_{2}$ and $95 \%$ humidity until traumatisation on the following day. Afterwards, the explants were cultivated for up to $14 \mathrm{~d}$ in serum-free medium [DMEM, $1 \%$ sodium pyruvate, $0.5 \%$ L-glutamine, $1 \%$ non-essential amino acids, $0.5 \%$ penicillin/streptomycin and $0.1 \%$ ITS (Sigma-Aldrich)]. All medium components were purchased from Biochrom (Berlin, Germany) unless specified otherwise.

\section{Impact loading and subsequent treatment}

Cartilage explants from tissue of 8 patients (mean age 64 , range 54-74 years) were subjected to a defined impact energy of $0.59 \mathrm{~J}$ by using a drop-tower model, as previously described (Riegger et al., 2016). Impacted cartilage explants were incubated with and without therapeutic additives: $100 \mathrm{ng} / \mathrm{mL}$ rhIGF-1 (= IGF-1), 200 ng/mL rhFGF18 (= FGF18), 100 ng/mL rhBMP7 (= BMP7) (Peprotech) or 2 mM NAC (Sigma-Aldrich). Fresh additives were provided concomitantly with medium change every 2-3 d. The concentrations of the therapeutics were selected based on previous studies (Riegger et al., 2016; Riegger et al., 2017).

\section{Isolation and cultivation of CSPCs and chondrocytes}

Cells were isolated from human cartilage (see above) of 18 patients (mean age 67, range 50-80 years), according to Koelling et al. (2009). In short, thin cartilage slices were prepared from macroscopically intact tissue regions of the femoral condyles and placed in a 6-well culture dish with basal medium (DMEM, $10 \%$ FCS, $1 \%$ penicillin/streptomycin, $1 \%$ L-glutamine). A cell strainer (BD GmbH) was used to keep cartilage slices down on the well bottom. After outgrowth from cartilage tissue, CSPCs were split at a confluence of $80 \%$ and used at passage 3 to 4 .

Chondrocytes were isolated from human cartilage of 4 patients (mean age 69, range 61-80 years) by enzymatic digestion. In short, full-thickness cartilage was minced and digested for 45 min with $0.2 \%$ pronase (Sigma-Aldrich) and overnight with $0.025 \%$ collagenase (Sigma-Aldrich). After washing with PBS and filtration through a $40 \mu \mathrm{m}$ cell strainer (BD GmbH), cells (passage 0) were cultured in serum-containing chondrocyte medium (see above). Chondrocytes were split at a confluence of $80 \%$ and used at passage 1 .

\section{Flow cytometry analysis}

To estimate the number of cells carrying CSPCassociated surface markers within the cartilage 14 $\mathrm{d}$ after trauma, cells were released from the ECM by enzymatic digestion using the method described in the previous section for chondrocyte isolation. Unimpacted explants served as controls. To obtain adequate numbers of cells, 4 to 5 punches were used for each condition (control, trauma with and without treatment). Isolated cells were immunocytologically stained on ice, for $30 \mathrm{~min}$ in the dark, with antibodies against CSPC-associated surface markers, CD45 and species-matched isotype controls, respectively. CD9, CD45, CD73, CD166 and IgG1 $\kappa$ were obtained from BD Bioscience (Heidelberg, Germany), CD105, Stro-1, MSCA-1 and IgM from BioLegend (Fell, Germany), IgG2a and IgG1 from R\&D Systems (Minneapolis, MN, USA) and CD90 from eBioscience (Frankfurt, Germany). Compositions of the panels and fluorescent labelling of the antibodies are listed in Table 1. For cytometric detection of pronase-sensitive CD105 (Diaz-Romero et al., 2005), freshly isolated cartilage cells were pre-incubated for $24 \mathrm{~h}$ in serumcontaining medium to allow recovery of the surface receptor prior to staining. The evaluation of all other surface marker was performed immediately after digestion. A minimum of $2 \times 10^{4}$ cells was analysed on a Becton Dickinson FACSCalibur flow cytometer (BD Biosciences), with dual-laser technology and characterised by four-colour immunofluorescence, using the corresponding software CellQuest version 5.2.1. The percentage of positively stained cells was calculated as $\mathrm{CD}^{+}$cells minus the isotype control (a maximum of $1 \%$ isotype control ${ }^{+}$cells was accepted).

\section{Chondrogenic differentiation and histological assessment}

For chondrogenic differentiation, $2.5 \times 10^{5} \mathrm{CSPCs}$ were pelleted by centrifugation and cultivated as pellet culture for $28 \mathrm{~d}$ in CDM [DMEM supplemented with $4.5 \mathrm{~g} / \mathrm{L}$ glucose and Ham's F12 (1: 1), $100 \mathrm{U} /$ 
Table 2. Specification of the scoring system. The histologic assessment criteria type II collagen, COMP, PG staining intensities and pellet size (diameter) were classified from 0 (= evidence for failed chondrogenic differentiation) to 3 and 4 (= evidence for successful chondrogenic differentiation). Scoring categories derived from the Bern score are indicated by an asterisk.

\begin{tabular}{|l|c|}
\hline \multicolumn{1}{|c|}{ Scoring categories } & Score \\
\hline I) Pellet size (diameter) & \\
\hline$<1000 \mu \mathrm{m}$ & 0 \\
\hline$>1000 \mu \mathrm{m}$ & 1 \\
\hline$>1500 \mu \mathrm{m}$ & 2 \\
\hline$>2000 \mu \mathrm{m}$ & 3 \\
\hline$>2500 \mu \mathrm{m}$ & 4 \\
\hline II, III, IV) Type II collagen/COMP/safranin O* $^{*}$ staining intensities & \\
\hline No stain & 0 \\
\hline Weak stain (>5\% positive) & 1 \\
\hline Scattered moderate stain $(>25 \%$ positive) & 2 \\
\hline Even moderate stain $(>50 \%$ positive) & 3 \\
\hline Even intensive stain (> 85\% positive) & 4 \\
\hline V) Cell-cell distance (matrix production)* & \\
\hline High cell density; no matrix between cells & 0 \\
\hline High cell density; little matrix between cells & 1 \\
\hline Moderate cell density; little matrix between cells & 2 \\
\hline Low cell density; extensive matrix between cells & 3 \\
\hline VI) Cell morphology* & \\
\hline Condensed/necrotic/pycnotic bodies & 0 \\
\hline Spindle/fibrous & 1 \\
\hline Mixed spindle/fibrous and rounded/chondrogenic & 2 \\
\hline Majority rounded/chondrogenic & 3 \\
\hline
\end{tabular}

Table 3. Specification of the therapeutic additives and differently conditioned media used for CSPC stimulation.

\begin{tabular}{|l|c|c|}
\hline Medium/therapeutic additives & Working concentration & Abbreviation \\
\hline N-acetyl cysteine & $2 \mathrm{mM}$ & NAC \\
\hline Insulin-like growth factor 1 & $100 \mathrm{ng} / \mathrm{mL}$ & IGF-1 \\
\hline Fibroblast growth factor 18 & $200 \mathrm{ng} / \mathrm{mL}$ & FGF18 \\
\hline Bone morphogenetic protein 7 & $100 \mathrm{ng} / \mathrm{mL}$ & BMP7 \\
\hline CC medium obtained from & & CC \\
- unimpacted cartilage explants & & TC \\
- impacted cartilage explants & mixed $1: 1$ with & TNC \\
- impacted NAC-treated cartilage explants & serum-free medium & TIC \\
- impacted IGF1-treated cartilage explants & & TFC \\
- impacted FGF18-treated cartilage explants & & TBC \\
\hline TC and retrospective addition of & & TC + NAC \\
- NAC & & TC + IGF-1 \\
- IGF-1 & mixed $1: 1$ with & TC + FGF18 \\
- FGF18 & serum-free medium & TC + BMP7 \\
\hline
\end{tabular}

$\mathrm{mL}$ penicillin/streptomycin, $40 \mathrm{ng} / \mathrm{mL}$ L-proline, $0,1 \mu \mathrm{mol} / \mathrm{L}$ dexamethasone, $50 \mu \mathrm{g} / \mathrm{mL}$ ascorbic acid, $10 \mu \mathrm{L} / \mathrm{mL}$ ITS (Sigma-Aldrich), $10 \mathrm{ng} / \mathrm{mL}$ rhTGF- $\beta 3$ (= TGF- $\beta 3$; R\&D Systems) and $10 \mathrm{ng} / \mathrm{mL}$ rhBMP6 (= BMP6; Peprotech)]. During the first week, TGF- 33 and BMP6 were freshly added every day; afterwards - similarly to NAC (2 mM) and/or IGF-1
(100 ng/mL), FGF18 (200 ng/mL) or BMP7 (100 ng/ $\mathrm{mL}$ ) - concomitantly with medium change every 2-3 d. For the IHC, $3.5 \mu$ m-thick paraffin-embedded sections were dewaxed, rehydrated and pre-digested for $30 \mathrm{~min}$ at $37^{\circ} \mathrm{C}$ for antigen retrieval with pepsin $(1 \mathrm{mg} / \mathrm{mL}$ in $0.5 \mathrm{M}$ acetic acid), in case of collagen II staining, or with hyaluronidase $(2 \mathrm{mg} / \mathrm{mL}$ in sodium 
acetate $\mathrm{pH} 5$ ), in case of COMP staining. Sections were treated with $3 \%$ hydrogen peroxide before starting the staining with the Dako LSAB2 SystemHRP kit (Dako) and antibodies against collagen II (AF5710; Acris, Hiddenhausen, Germany) or COMP (provided by F. Zaucke, Frankfurt, Germany). For histological staining of proteoglycans, safranin $\mathrm{O}$ (Fisher Scientific) was used. In all samples, a final staining of cell nuclei by Gill's haematoxylin No 3 (Sigma-Aldrich) was performed. To evaluate chondrogenic differentiation, the Bern scoring was extended by further categories to an appropriately designed scoring system as itemised in Table 2 (Grogan et al., 2006).

\section{Stimulation of isolated cartilage cells}

Conditioned medium was collected 24 h or $7 \mathrm{~d}$ (last medium change $48 \mathrm{~h}$ before) after trauma from unimpacted or impacted human cartilage tissue incubated with and without therapeutic additives in $1 \mathrm{~mL}$ per well of serum-free medium in a 24-well plate (one cartilage explant per well). In the case of the CC medium used for the chondrogenic differentiation, explants were cultivated in CDM accordingly. CSPCs/ chondrocytes were seeded on 48-well cell culture plates $\left(0.5 \times 10^{5}\right.$ cells $\left./ \mathrm{cm}^{2}\right)$ and incubated in serumcontaining medium for $6 \mathrm{~h}$ to adhere. Afterwards, complete medium was discarded and replaced by serum-free medium for adaptation. The next day, isolated CSPCs/chondrocytes were stimulated for $48 \mathrm{~h}$ by conditioned medium, mixed $1: 1$ with serumfree medium to a total volume of $300 \mu \mathrm{L}$. To consider the sole influence of the therapeutic intervention, the therapeutics were retrospectively added to CSPCs stimulated with TC medium or directly added to unstimulated CSPCs. The different approaches and corresponding abbreviations are listed in Table 3.

\section{Gene expression analysis}

Total RNA isolation of cell lysates by means of the RNA Mini Kit and subsequent reverse transcription by means of the Omniscript RT Kit were performed in accordance with the manufacturer's instructions (QIAGEN).

Relative gene expression levels of the target genes were determined by quantitative real-time polymerase chain reaction (qRT-PCR), using the $2^{-\Delta \Delta \mathrm{Ct}}$ method and the StepOnePlus ${ }^{\mathrm{TM}}$ Real-Time PCR System (Applied Biosystems). Target sequences were detected using the TaqMan ${ }^{\circledR}$ Gene Expression Master Mix and the following TaqMan ${ }^{\circledR}$ Gene Expression Assays (both Applied Biosystems): TSG6 (TNFAI P6), HS01113602; CXCL1 (Gro- $\alpha$ ), HS00605382; IL-8 (CXCL8), HS00174103; IL-1ß, HS00174097; RAGE (AGER), HS005422584; TLR4, HS00152939; IL-10, HS00961622; TNF- $\alpha$, HS1113624.

In case of the endogenous controls, Power SYBRTM Green PCR Master Mix (Applied Biosystems) was used for the $18 \mathrm{~S}$ rRNA, with the 5'-CGCAGCTAGGAATAATGGAATAGG-3' (forward) and 5'-CATGGCCTCAGTTCCGAAA-3' (reverse) primers and Platinum ${ }^{\mathrm{TM}} \mathrm{SYBR}^{\mathrm{TM}}$ Green $\mathrm{qPCR}$ SuperMix-UDG (Invitrogen) was used for GAPDH, with the 5'-TGGTATCGTGGAAGGACTCATG-3' (forward) and 5'-TCTTCTGGGTGGCAGTGATG-3' (reverse) primers. Target mRNA-expression was normalised to the endogenous controls.

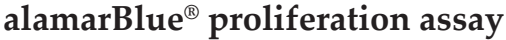

Quantitative measurement of cell proliferation was attained by means of an alamarBlue ${ }^{\circledR}$ assay (BioRad). The conversion of non-fluorescent resazurin to fluorescent resorufin by $\mathrm{FMNH}_{2}, \mathrm{FADH}_{2}, \mathrm{NADH}$, NADPH and cytochromes, released during cellular respiration, is proportional to the number of living cells. After $48 \mathrm{~h}$, wells were rinsed with PBS and cells were incubated for $4 \mathrm{~h}$ at $37^{\circ} \mathrm{C}$ in $200 \mu \mathrm{L}$ of a $5 \%$ alamarBlue ${ }^{\circledR}$ solution (in serum-free medium). After the incubation period, the fluorescence intensities were detected at $550 \mathrm{~nm}$ excitation and $590 \mathrm{~nm}$ emission by using the multimode microplate reader Infinite M200 Pro (Tecan Austria GmbH, Groedig, Austria). Blank values (5\% alamarBlue ${ }^{\circledR}$ solution in empty well) were subtracted from measured values.

\section{In vitro wound healing/scratch assay}

CSPCs were grown to a confluent monolayer on 24-well culture plates. After creating a scratch in the cell layer with a $200 \mu \mathrm{L}$ pipette tip, cell debris were removed by rinsing with PBS. Cells were cultivated in basal medium mixed $1: 1$ with serum-free TC medium, with $5 \%$ FCS. The closure of the scratch was documented by phase contrast microscopy after $24 \mathrm{~h}$ and $48 \mathrm{~h}$ and was quantified by counting the cells present in the initial gap.

\section{Chemotaxis/Boyden chamber assay}

Directed cell migration was analysed by a modified Boyden chamber assay, using a 48-well microchemotaxis chamber and polycarbonate filters (8 $\mu \mathrm{m}$ pores; both: NeuroProbe Inc., Baltimore, MD, USA), as previously described (Fiedler et al., 2006). TC medium was diluted in DMEM $(1: 1)$, filled into the lower compartment of the chemotaxis chamber and covered with the chemotaxis filter. The upper wells were loaded with $50 \mu \mathrm{L}$ cell suspension in DMEM $\left(1 \times 10^{4}\right.$ cells $)$ and incubated for $4 \mathrm{~h}$ at $37^{\circ} \mathrm{C}, 5 \% \mathrm{CO}_{2}$ in $95 \%$ humidity. DMEM in the lower well served as a negative control (basal migration). The filter was removed, washed with PBS and non-migrated cells on the upper side of the filter were removed using a cell scraper. The migrated cells on the lower side were fixed with $4 \%$ formaldehyde, stained with Giemsa solution (Merck) and counted ( $n=4$ technical replicates).

\section{Statistical analysis}

Statistical analysis of results from at least three independent experiments (biological replicates) was performed using GraphPad Prism version 6.0h. Data sets with $n \geq 5$ were tested for outliers with the Grubbs outlier test. Outliers were not included in the 
statistical analysis. The applied statistic method can be found in the caption of the corresponding figures. Significant level was set to $p=0.05$.

\section{Results}

Regenerative potentials of CSPCs after cartilage trauma

MSC-related surface markers CD9, CD105, CD166 and MSCA-1 were significantly enhanced after cartilage trauma

To estimate the influence of trauma and subsequent treatment on the CSPC population within the corresponding cartilage explants, whole cell isolation was achieved by enzymatic digestion $14 \mathrm{~d}$ post trauma. The histogram of the isolated cells' data noticeably shifted in the impacted cartilage explants (red curve, Fig. 1a-h) as compared to the unimpacted cartilage explants (green curve, Fig. 1a-h). In fact, isolated cartilage cells from impacted tissue exhibited a significantly higher incidence of CD9- (3.4-fold, $p=0.015)$, CD105- (1.5-fold, $p=0.008)$, CD166- (2.4fold, $p=0.042)$ and MSCA-1- (1.9-fold, $p=0.045)$ positive cells (Fig. 1i). Treatment of impacted cartilage explants with FGF18 resulted in a significant increase in $\mathrm{CD}_{166^{+}}$cells as compared to untreated tissue (2.3-fold, $p=0.008$ ) (Fig. 1j).
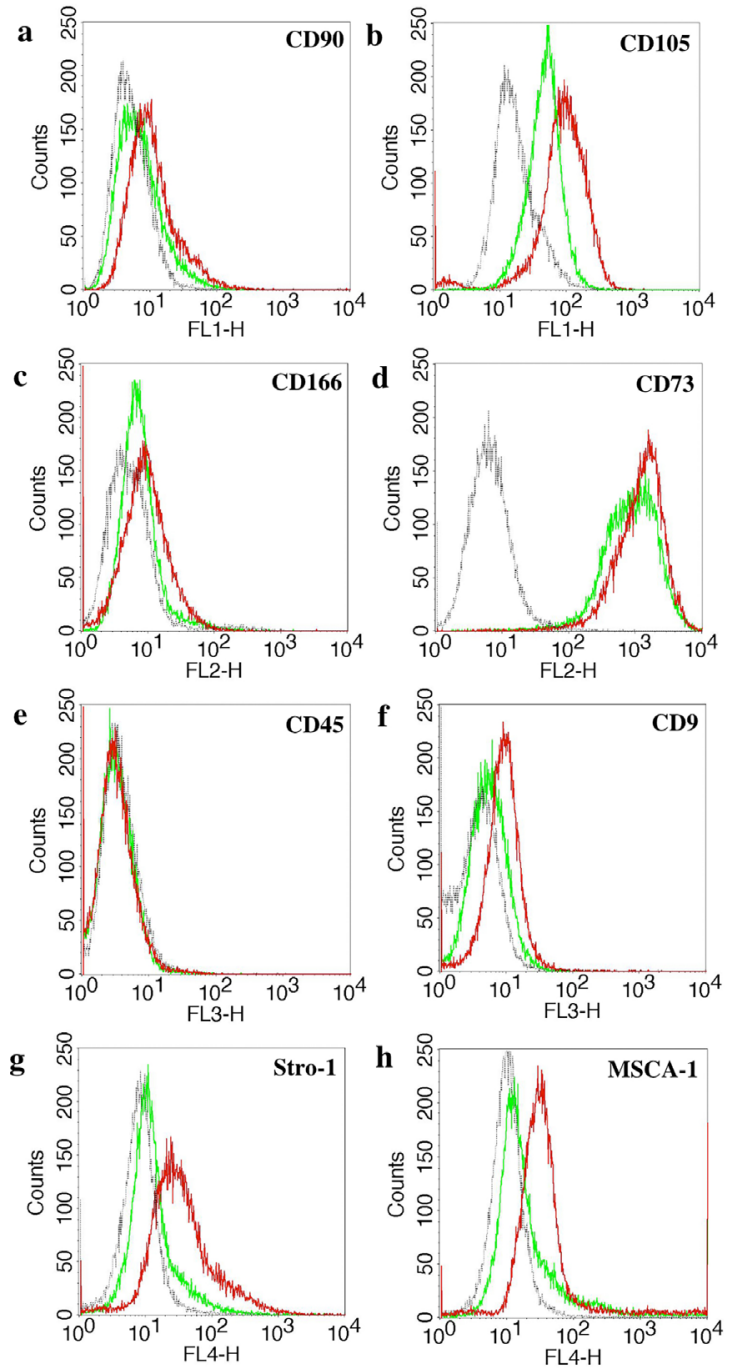
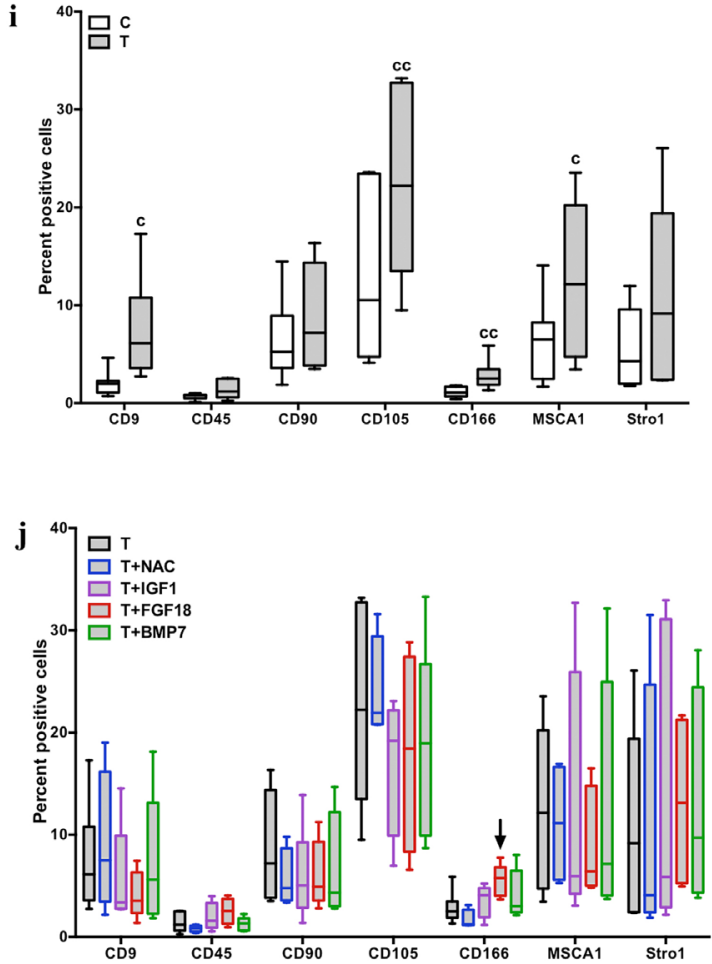

Fig. 1. Effect of trauma with or without subsequent administration of therapeutics on the percentage of CSPC-marker positive cells. (a-h) Whole cartilage cell isolates of impacted and unimpacted cartilage explants were analysed by means of flow cytometry for CSPC-associated surface markers CD9, CD90, CD105, CD166, MSCA-1 and Stro-1, 14 d after impact. Haematopoietic surface marker CD45 served as negative control. (a-h) Exemplary histograms of single surface markers additionally including CD73 as positive control; grey line = isotype control, green line = cells derived from unimpacted cartilage, red line $=$ cells derived from impacted cartilage. (i) Statistical analysis of the overall results; $n \geq 7$. Significant differences from unimpacted cartilage explant (vs. C) are depicted as ${ }^{c} p<0.05,{ }^{c c} p<0.01$. (j) Percentage of CSPC-associated surface marker positive cells derived from impacted versus impacted and treated cartilage explants; $n \geq 4$. Significant differences from untreated impacted cartilage explant (vs. T) are indicated with black arrows. Statistical analysis was performed by means of a Student's $t$-test. Results are expressed as boxplots; median with whiskers min to max. $\mathrm{C}=$ unimpacted cartilage, $\mathrm{T}=$ impacted cartilage. 
Proliferation, migration and in vitro wound healing capacities were enhanced in TC-medium-stimulated CSPCs, although, to some extent, they could be differentially influenced by therapeutic intervention

Regenerative capacities of CSPCs in response to soluble factors released after trauma was estimated by means of an in vitro wound healing assay (Fig. 2a,b), which comprises undirected migration and proliferative activity (Jonkman et al., 2014). Directed migration (towards a chemotactic gradient) and proliferation of the CSPCs were additionally quantified by Boyden chamber assay (Fig. 2c) and alamarBlue $^{\circledR}$ assay (Fig. 2d), respectively. After $24 \mathrm{~h}, \mathrm{TC}$-medium-stimulated CSPCs exhibited significant closure of the artificially applied scratch lesion ( $p<0.0001$ vs. basal; $p=0.0009$ vs. unimpacted;
$24 \mathrm{~h}$

a

Basal

CC

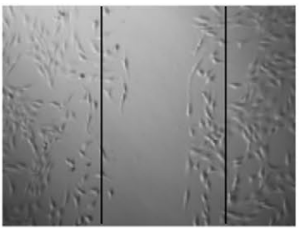

TC



TNC

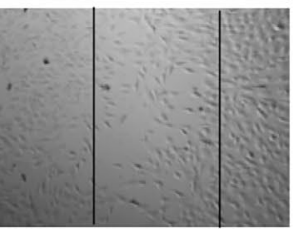

TIC
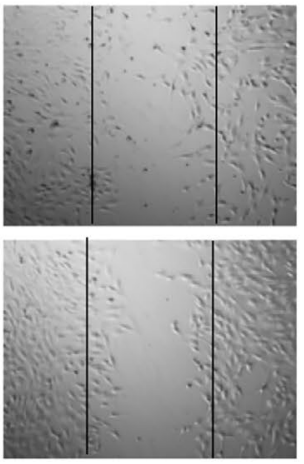

TFC

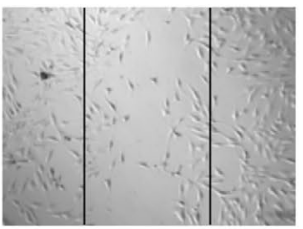

TBC

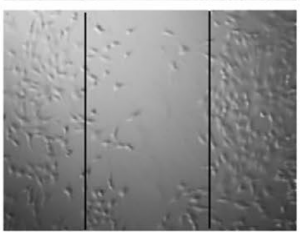

$48 \mathrm{~h}$

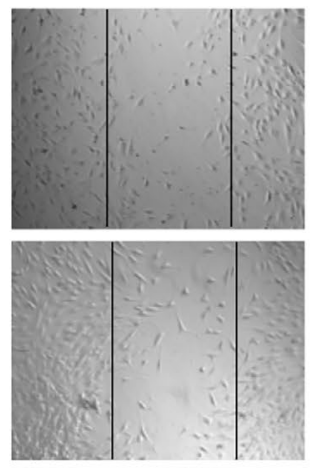

b
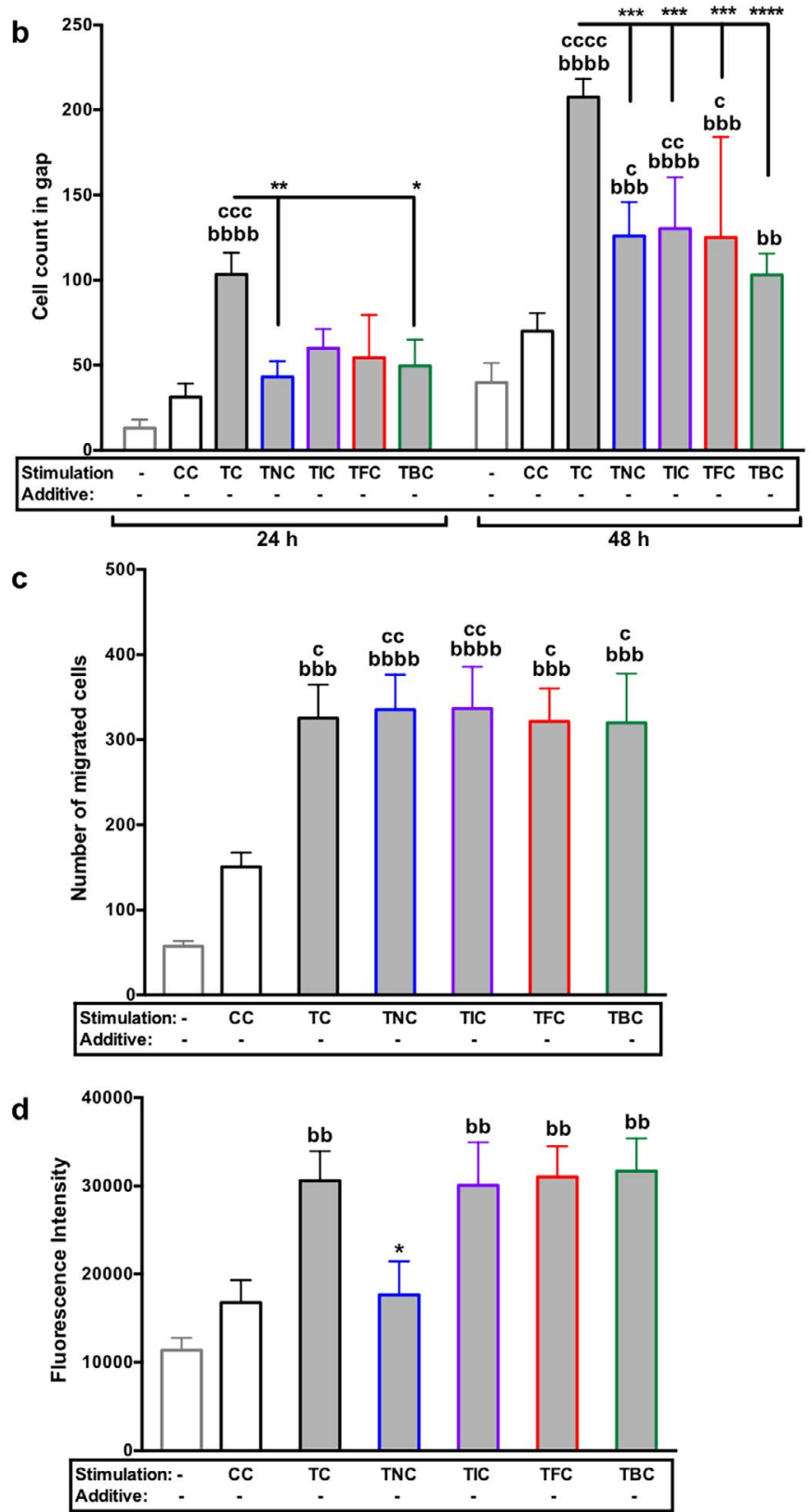

Fig. 2. Proliferation, chemotaxis and wound healing activity of CSPCs after stimulation by TC medium with and without therapeutic additives. CSPCs were stimulated with cartilage-conditioned media obtained from unimpacted (CC), impacted (TC) or impacted and treated cartilage explants (TNC, TIC, TFC, TBC). (a) Representative images of the wound healing/scratch assay $24 \mathrm{~h}$ and $48 \mathrm{~h}$ after stimulation. (b) The corresponding statistical analysis was performed by means of a two-way ANOVA with Bonferroni post-hoc test; $n \geq 3$. (c) Statistic analysis of CSPC chemotaxis measured by Boyden chamber assay; $n=3$. (d) Proliferation of CSPCs $48 \mathrm{~h}$ after stimulation was assumed to correlate with fluorescence intensity of resorufin of the alamarBlue $^{\circledR}$ assay; $n \geq 4$. Both statistical analyses were performed by means of a one-way ANOVA with Bonferroni post-hoc test. Significant differences among the groups were depicted as ${ }^{\mathrm{bb}} p<0.01$, ${ }^{\mathrm{bbb}} p<0.001$, bbbb $p<0.0001$, vs. basal; ${ }^{c} p<0.05,{ }^{c c} p<0.01,{ }^{c c c} p<0.001,{ }^{c c c c} p<0.0001$, vs. CC; ${ }^{*} p<0.05,{ }^{* *} p<0.01,{ }^{* * *} p<0.001$, **** $p<0.0001$, vs. TC. Results are expressed as column bars; mean and SEM. 
Fig. 2b), which was comparatively lower in TNC$(p=0.0073)$ or TBC-stimulated cells $(p=0.0428)$. After $48 \mathrm{~h}$, the gap of TC-stimulated CSPCs was highly repopulated ( $p<0.0001$ vs. basal and unimpacted). This effect was significantly lower after stimulation with any treated cartilage culture medium (TNC and TFC: $p=0.0004$; TIC: $p=0.0003$; TBC: $p<0.0001$, all vs. TC medium).

In comparison to unstimulated CSPCs, cell proliferation was significantly enhanced $48 \mathrm{~h}$ after stimulation with TC medium $(p=0.001)$, TIC $(p=0.0039), \operatorname{TFC}(p=0.0024)$ and TBC $(p=0.0017)$ by around 2.7-fold each (Fig. 2a). Stimulation with CC medium or TNC had no significant influence on the mitotic activity, although, traumaassociated enhancement of cell proliferation was significantly lower in TNC-stimulated CSPCs (-1.7fold vs. TC, $p=0.0387)$. Additional Boyden chamber analysis revealed that chemotaxis of CSPCs was not significantly enhanced by CC medium, but by all media obtained from traumatised cartilage regardless of the subsequent treatment: vs. basal, TC medium: $p=0.0001$, TNC and TIC: $p<0.0001$, TFC and TBC: $p=0.0002$; vs. CC medium, TC: $p=0.0128$, TNC:

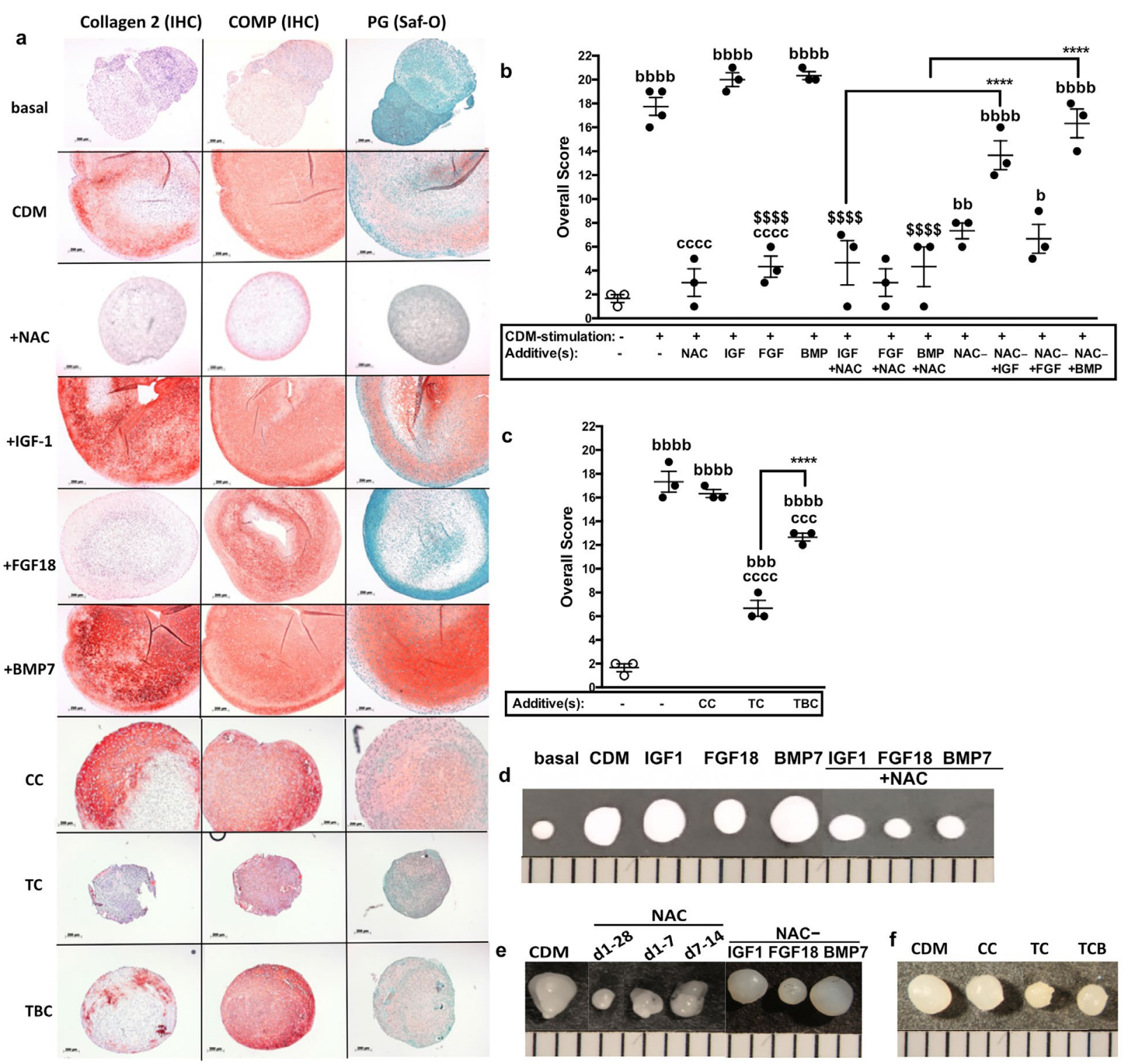

Fig. 3. Assessment of chondrogenic differentiation of CSPCs with and without therapeutic additives. (a) Light microscopy images from type II collagen IHC staining, COMP IHC staining and proteoglycan (safranin O) staining. (b,c) Statistical analysis of the overall score, comprising pellet size (diameter), staining intensities of type II collagen/COMP/safranin O-fast green, as well as Bern score categories (matrix produced/cell morphology). Statistical analysis was performed by means of a one-way ANOVA with Bonferroni post-hoc test. Significant differences among the groups were depicted as ${ }^{\mathrm{b}} p<0.05,{ }^{\mathrm{bb}} p<0.01$, ${ }^{\mathrm{bbb}} p<0.001,{ }^{\text {bbbb }} p<0.0001$, vs. basal; ${ }^{c c} p<0.001$, ${ }^{c c c c} p<0.0001$, vs. CC; ${ }^{* * * *} p<0.0001$ vs. TC and vs. nondeprived, respectively; $\$ \$ \$ \$ 0.0001$ vs. IGF-1 and BMP7, respectively. Results are given as scattered dot plot; mean and SEM; CDM: $n=4$, all others $n=3$; unfilled circles = cultured without CDM; filled circles = cultured with CDM. (d-f) Images of cell pellets after harvest (day 27). 
Table 4. Assessment of chondrogenic differentiation of CSPCs. Results of individual categories given as mean \pm standard deviation.

\begin{tabular}{|c|c|c|c|c|c|c|}
\hline Approach & Diameter & Collagen II & COMP & $\begin{array}{c}\text { Proteoglycan } \\
\text { (safranin O) }\end{array}$ & $\begin{array}{c}\text { Matrix } \\
\text { produced }\end{array}$ & $\begin{array}{c}\text { Cell } \\
\text { morphology }\end{array}$ \\
\hline Basal & $0.33 \pm 0.58$ & 0.0 & $0.67 \pm 0.58$ & 0.0 & $0.33 \pm 0.58$ & $1.0 \pm 0$ \\
\hline CDM & $3.25 \pm 0.58$ & $2.5 \pm 0.58$ & $4.0 \pm 0.0$ & $3.25 \pm 0.5$ & $2.5 \pm 0.58$ & $2.35 \pm 0.58$ \\
\hline NAC & $0.33 \pm 0.58$ & 0.0 & $1.5 \pm 0.7$ & 0.0 & $0.67 \pm 0.58$ & $1.0 \pm 0.0$ \\
\hline IGF1 & $3.67 \pm 0.58$ & $3.33 \pm 0.58$ & $3.67 \pm 0.58$ & $4.0 \pm 0.0$ & $3.0 \pm 0.0$ & $2.33 \pm 0.58$ \\
\hline FGF18 & $1.33 \pm 0.58$ & 0.0 & $1.67 \pm 1.53$ & 0.0 & 0.0 & $1.0 \pm 0.0$ \\
\hline BMP7 & $3.33 \pm 0.58$ & $3.67 \pm 0.58$ & $3.33 \pm 0.58$ & $4.0 \pm 0.0$ & $3 \pm 0.0$ & $3.0 \pm 0.0$ \\
\hline IGF1+NAC & $1.0 \pm 1.0$ & $0.33 \pm 0.58$ & $1.3 \pm 1.15$ & $0.33 \pm 0.58$ & $0.67 \pm 0.58$ & $1.0 \pm 0.0$ \\
\hline FGF18+NAC & $0.67 \pm 0.58$ & $0.33 \pm 0.58$ & $1.0 \pm 1.0$ & $0.33 \pm 0.58$ & $0.33 \pm 0.58$ & $1.0 \pm 0.0$ \\
\hline BMP7+NAC & $0.67 \pm 0.58$ & 0.0 & $1.67 \pm 1.53$ & $0.33 \pm 0.58$ & $0.67 \pm 0.58$ & $1.0 \pm 0.0$ \\
\hline NAC- & $1.0 \pm 0$ & $0.67 \pm 0.58$ & $2.67 \pm 1.16$ & $0.67 \pm 0.58$ & $1.33 \pm 0.58$ & $1.33 \pm 0.58$ \\
\hline NAC-/IGF1 & $1.33 \pm 0.58$ & $1.67 \pm 0.58$ & $3.0 \pm 0.0$ & $3.33 \pm 1.16$ & $2.33 \pm 0.58$ & $2.0 \pm 0.0$ \\
\hline NAC-/FGF18 & $1.0 \pm 0.0$ & $0.33 \pm 0.58$ & $2.33 \pm 1.15$ & $0.33 \pm 0.58$ & $1.33 \pm 0.58$ & $1.33 \pm 0.58$ \\
\hline NAC-/BMP7 & $2.0 \pm 0.0$ & $2.0 \pm 1.0$ & $3.33 \pm 0.58$ & $4.0 \pm 0.0$ & $2.67 \pm 0.58$ & $2.33 \pm 0.58$ \\
\hline CC & $1.33 \pm 0.58$ & $2.67 \pm 0.58$ & $3.67 \pm 0.58$ & $3.33 \pm 0.58$ & $2.67 \pm 0.58$ & $2.67 \pm 0.58$ \\
\hline TC & 0.0 & $0.33 \pm 0.58$ & $2 \pm 0.0$ & $2 \pm 0.0$ & $1.0 \pm 0.0$ & $1.33 \pm 0.58$ \\
\hline TBC & $1.0 \pm 0.0$ & $1.33 \pm 0.58$ & $3.33 \pm 0.58$ & $3.0 \pm 0.0$ & $2.0 \pm 0.0$ & $2.0 \pm 0.0$ \\
\hline
\end{tabular}

$p=0.0079$, TIC: $p=0.0074$, TFC: $p=0.0156$, TBC: $p=0.0167$.

Chondrogenic differentiation of CSPCs was suppressed by TC, NAC or FGF18 simulation but improved by IGF-1 or $B M P 7$

Additional co-stimulation of CDM-stimulated CSPCs influenced chondrogenic differentiation in different ways, as demonstrated by chondrogenic marker staining intensities (Fig. 3a), pellet size, ECM formation and cell proliferation (Dexheimer et al., 2012) (Fig. 3d-f). Histological assessment (Fig. 3b,c and Table 4) revealed that additional stimulation with the chondroanabolic IGF-1 and BMP7 enhanced the type II collagen biosynthesis as compared to CDM (Table 4; BMP7: $p=0.0115$, IGF-1: $p=0.0709$ ). In contrast, chondrogenic markers were significantly decreased after addition of NAC and FGF18, as reflected in the overall score $(p<0.0001$ each vs. CDM, BMP7 and IGF-1; Fig. 3b). Attempts to counterbalance NAC-mediated suppression of the chondrogenic differentiation by simultaneous stimulation with IGF-1, FGF18 or BMP7 failed (Fig. 3b). However, after depriving NAC on day 8 , chondrogenic characteristics recovered partially (NAC- vs. NAC, $p=0.0683$ ), as observed $21 \mathrm{~d}$ after deprivation of NAC. Additional stimulation with IGF-1 or BMP7 further improved the differentiation after deprivation of the antioxidant (NAC $-v s$. NAC-/IGF-1 $p=0.0034$; NACvs. NAC-/BMP7, $p<0.0001)$.

Co-stimulation with CC-CDM had no significant effect on the chondrogenic differentiation of CSPCs, although, addition of TC-CDM significantly decreased the overall score (Fig. 3c; TC vs. CDM, $p<0.0001)$. This trauma-mediated impairment of the chondrogenic differentiation could partly be compensated by BMP7-treatment of impacted cartilage explants, as demonstrated by co-stimulation with TBC-CDM (overall score TBC vs. TC: $p<0.0001$ ).

\section{Immunomodulatory potentials of CSPCs after cartilage trauma}

Gene expression of immunomodulatory mediators was enhanced in TC-medium-stimulated CSPCS, although it could be attenuated by immediate therapeutic intervention To investigate a possible immunomodulatory response of CSPCs affecting both injury-associated factors and therapeutic intervention, relative gene expression levels of chemokines $I L-8$ and CXCL1 (Fig. 4a-c), pro-inflammatory cytokines TNF- $\alpha$ and $I L-1 \beta$ (Fig. 4d-f), anti-inflammatory mediators $I L-10$ and TSG-6 (Fig. 4g-i) and PRRs RAGE and TLR4 (Fig. $4 \mathbf{j}-1)$ were evaluated $48 \mathrm{~h}$ after CSPC stimulation with differently conditioned media (Table 3).

TC medium stimulation significantly increased the gene expression of IL-8 (2.7-fold, $p=0.0009)$, CXCL1 (2-fold, $p=0.0009)$, IL-10 (2-fold, $p=0.0072)$, TSG6 (1.5fold, $p=0.0397)$, TLR4 (2-fold, $p=0.0175$ ) and RAGE (2.3-fold, $p=0.0002$ ) as compared to the corresponding gene expression in CC-medium-stimulated CSPCs (Fig. $4 \mathbf{a}, \mathbf{d}, \mathbf{g}, \mathbf{j}) . I L-1 \beta$ was not consistently expressed in CSPCs, unless cells were stimulated with TC medium (about 15-fold enhanced). Stimulation with media obtained from treated cartilage explants did not induce the expression of the analysed genes, except for TLR4, which was only alleviated by BMP7 and enhanced by FGF18 (significant differences between TC medium and TNC/TIC/TFC/TBC are given in Table 5). Overall, gene expression of TNF- $\alpha$ was generally low ( $>40$ cycles) and could not be detected reliably.

However, gene expression of TC-mediumstimulated CSPCs was differentially influenced by costimulation with the therapeutics (Fig. 4b,e,h,k). IGF- 



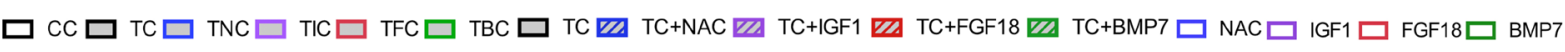

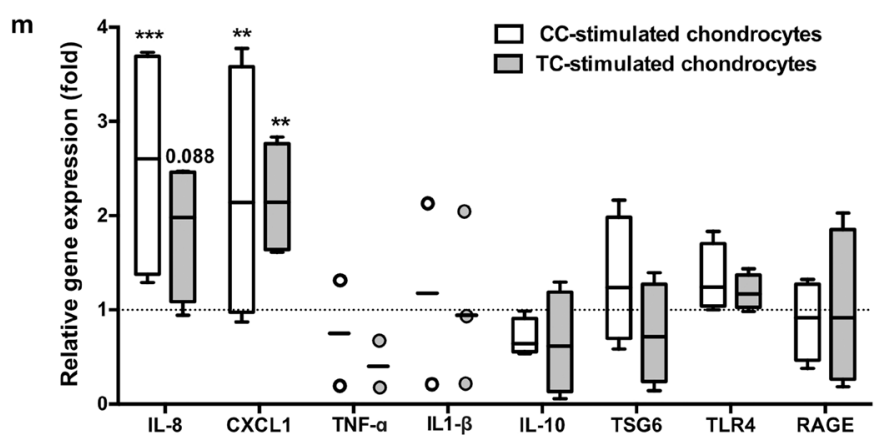

Fig. 4. Gene expression of CSPCs and chondrocytes after stimulation by TC medium with and without therapeutic treatment. Expression levels of (a-c) chemokines IL-8 and CXCL1, (d-f) pro-inflammatory cytokines TNF- $\alpha$ and IL-1 $\beta$, (g-i) anti-inflammatory modulators IL-10 and TSG6 and (j-1) PRRs TLR4 and RAGE were quantified by means of qRT-PCR. CSPCs were stimulated for $48 \mathrm{~h}$ with $(\mathbf{a}, \mathbf{d}, \mathbf{g}, \mathbf{j})$ CC medium obtained from unimpacted, impacted or impacted and treated cartilage explants. (b,e,h, $\mathbf{k})$ TC-stimulated CSPCs were co-stimulated with therapeutics. $(\mathbf{c}, \mathbf{f}, \mathbf{i}, \mathbf{l})$ Unstimulated CSPCs were exposed to therapeutic additives. Statistical analysis was performed by means of a Student's $t$-test. (m) Chondrocytes were stimulated with CC- and TC-medium for $48 \mathrm{~h}$ as comparative groups. Statistical analysis was performed by means of a two-way ANOVA with Bonferroni post-hoc test. Significant differences among the groups were depicted as follows: ${ }^{\mathrm{b}} p<0.05,{ }^{\mathrm{bb}} p<0.01$, bbb $p<0.001$, ${ }^{\mathrm{bbbb}} p<0.001$, vs. basal; ${ }^{\mathrm{cc}} p<0.05,{ }^{\mathrm{c}} p<0.01$, ${ }^{c c c} p<0.005$, cccc $p<0.001$, vs. CC; ${ }^{*} p<0.05,{ }^{* *} p<0.01,{ }^{* * *} p<0.001,{ }^{* * * *} p<0.0001$, vs. TC. Results are expressed as boxplots; median with whiskers $\min$ to $\max ; n=4$. 
Table 5. Differences among TC- and TNC-, TIC-, TFC-, TBC-stimulation on CSPC gene expression. Effects of CSPC stimulation with TNC, TIC, TFC or TBC on immunomodulation-associated gene expression after $48 \mathrm{~h}$. Results were compared to CSPCs exposed to medium obtained from impacted, untreated cartilage explants (TC). Statistical analysis was performed by means of a Student's $t$-test. n.d. $=$ not detected.

\begin{tabular}{|c|c|c|c|c|c|c|c|c|c|}
\hline & {$[v s$. TC] } & IL-8 & CXCL1 & TNF- $\alpha$ & IL-1ß & IL-10 & TSG6 & TLR4 & RAGE \\
\hline \multirow{2}{*}{ TNC } & Fold change & -2.7 & -2.4 & n.d. & n.d. & -1.4 & -2.0 & -1.3 & -2.7 \\
\cline { 2 - 11 } & $p$ & 0.0003 & 0.0049 & n.d. & n.d. & 0.1084 & 0.0027 & 0.1838 & 0.0002 \\
\hline \multirow{2}{*}{ TIC } & Fold change & -2.0 & -1.9 & n.d. & n.d. & -1.8 & -1.6 & -1.2 & -2.8 \\
\cline { 2 - 11 } & $p$ & 0.0009 & 0.01 & n.d. & n.d. & 0.0124 & 0.0252 & 0.6577 & 0.0004 \\
\hline \multirow{2}{*}{ TFC } & Fold change & -2.3 & -1.9 & n.d. & n.d. & -1.5 & -1.9 & 1.0 & -3.1 \\
\cline { 2 - 10 } & $p$ & 0.003 & 0.0016 & n.d. & n.d. & 0.1608 & 0.0044 & 0.878 & $<0.0001$ \\
\hline \multirow{2}{*}{ TBC } & Fold change & -2.6 & -2.1 & n.d. & n.d. & -2.2 & -1.7 & -2.8 & -5.0 \\
\cline { 2 - 10 } & $p$ & 0.0007 & 0.01 & n.d. & n.d. & 0.0027 & 0.0072 & 0.0027 & $<0.0001$ \\
\hline
\end{tabular}

1 enhanced TC-medium-induced gene expression of IL-8 (1.7-fold, $p=0.014)$. FGF18 induced IL-8 (3.3-fold, $p<0.0001$ ) and CXCL1 (1.6-fold, $p=0.049$ ) expression and reduced IL-10 (-1.9-fold, $p=0.0362)$ and RAGE $(-2.1$-fold; $p=0.016)$ expression. Addition of NAC or BMP7 significantly suppressed TC-medium-induced gene expression of CXCL1 (TC + NAC: - 1.7-fold, $p=0.0009$; TC + BMB7: -3.8 -fold, $p<0.0001)$. Further, BMP7 decreased the expression of IL-1 $\beta$ (TC + BMP7: - 6.1-fold, $p<0.0001), I L-8(-2.2$-fold, $p=0.003)$ and TLR4 (-1.8-fold, $p=0.05)$.

Comparable effects of the therapeutics were found in CSPCs cultivated in basal medium (Fig. $4 \mathbf{c}, \mathbf{f}, \mathbf{i}, \mathbf{l})$ : IGF-1 increased the gene expression of CXCL1 (1.5-fold, $p=0.042$ ) and FGF18 as compared to $I L-8$ (2-fold, $p=0.0007$ ) and CXCL1 (2.4-fold, $p<0.0001)$. While all therapeutics equally enhanced the mRNA levels of $I L-10$ (NAC: 2.6-fold, $p=0.0005$; IGF-1: 1.8-fold, $p=0.007$; FGF18: 2.1-fold, $p=0.0051$; BMP7: 2-fold, $p=0.0211$ ), only IGF-1 and FGF18 additionally induced the gene expression of TSG6 (IGF-1: 1.6-fold, $p=0.0043$; FGF18: 2.2-fold, $p<0.0001$ ) and IL-1 (IGF-1: 2.2-fold, $p=0.018$; FGF18: 4.3-fold, $p<0.0001)$. BMP7-stimulation of CSPCs decreased the gene expression of TLR4 and RAGE (both 1.5-fold, $p=0.0479$ and $p=0.049$, respectively).

Additional gene expression analysis of CC- and TC-medium-stimulated chondrocytes (Fig. 4m), which served as comparative group, revealed a partially significant response regarding the mRNA expression of IL-8 (CC: 2.6-fold, $p=0.0006$; TC: 2-fold, $p=0.0885$; both $v s$. basal) and CXCL1 (CC: 2.1-fold, $p=0.0067$; TC: 2.1-fold, $p=0.0096$; both vs. basal). However, in contrast to CSPCs, no significant difference between CC- and TC-medium stimulation was observed.

IL-6 release was enhanced in TC-medium-stimulated CSPCS, although suppressed by immediate therapeutic intervention

To further elucidate the immunomodulatory response of CSPCs after trauma and the possible influence of therapeutic additives, the release of IL-6 was quantified by ELISA (Fig. 5a-c).
The presence of IL- 6 within the CC medium was evaluated beforehand and could not be confirmed. CSPC stimulation with CC medium significantly enhanced IL-6 release as compared to unstimulated CSPCs cultivated in unconditioned medium (basal) (Fig. 5a; CC: 5.5-fold; TC: 31.2-fold, $p<0.0001$; TNC: 14.5 -fold, $p=0.008$; TIC: 13.8 -fold, $p=0.0095$; TFC: 8.3-fold, TBC: 9.2-fold). IL-6 release of TCmedium-stimulated CSPCs was significantly higher than CC-medium-stimulated CSPCs (5.7-fold, $p<0.0001)$. Medium of treated cartilage explants had significantly less effect on IL-6 secretion as compared to TC medium (TNC: -2.2 -fold, $p=0.0003$; TIC: - 2.3-fold, TFC: -3.7 -fold, TBC: -3.4 -fold; all others: $p<0.0001$ ).

Retrospective addition of FGF18 potentiated the TC-medium-induced release of IL-6 (TFC: 1.5-fold, $p=0.026)$, while BMP7 and IGF-1 had significant alleviating effects (TC + IFGF1: -3.4 -fold, $p<0.0001$; TC + BMP7: -2.8 -fold, $p=0.0002$ ) (Fig. 5b).

Stimulation with CC medium collected at day 7 had a reduced influence on IL-6 release (Fig. 5c; TC: $p<0.0001$; TIC: $p=0.0188 ; 7 \mathrm{~d}$ vs. 24 h). Nevertheless, TC medium stimulation increased IL-6 release by 20.8-fold and 5.2-fold (both $p<0.0001$ ), compared to unstimulated and CC-medium-stimulated CSPCs, respectively. Stimulation with medium obtained from treated cartilage explants resulted in attenuated IL-6 release (TC + NAC: -1.8 -fold, $p=0.0484$; TC + IFGF1: -1.9-fold, $p=0.0243$; TC + FGF18: -2.8 -fold, $p=0.0012$; TC + BMP7: - 2.1-fold, $p=0.0122$; all vs. TC).

\section{Discussion}

Although microarray analysis indicated that CSPCs may play a crucial role in pro-inflammatory response after cartilage injury (Zhou et al., 2014), conclusive scientific data confirming this presumption are lacking. In consideration of the known similarities between CSPCs and MSCs, the working hypothesis of this study was that CSPCs might possess MSClike immunomodulatory competences rather than solely pro-inflammatory ones. In fact, TC 
a
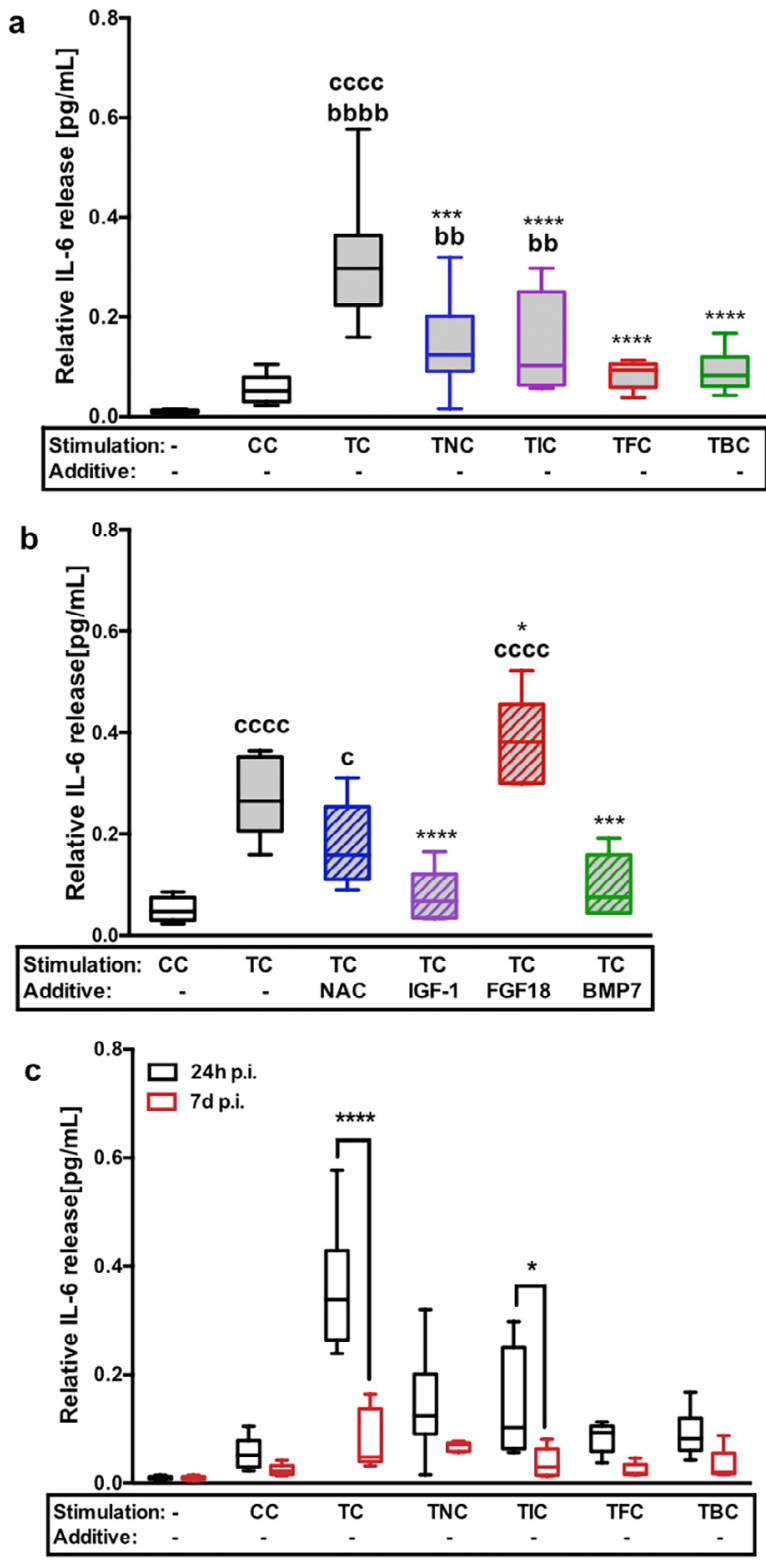

Fig. 5. IL-6 secretion after CSPC stimulation by TC medium with and without additional therapeutics. IL-6 release into the media of stimulated CSPCs was quantified by ELISA and normalised to the fluorescence intensity of resorufin (alamarBlue ${ }^{\circledR}$ assay). CSPCs were stimulated for $48 \mathrm{~h}$ with CC medium collected after (a) $24 \mathrm{~h}$ and (b) $7 \mathrm{~d}$ from unimpacted, impacted or impacted and treated cartilage explants; $n=8$. (c) TC-stimulated CSPCs were co-stimulated with therapeutics, $n=6$. Significant differences between the groups were depicted as ${ }^{\mathrm{b}} p<0.05$, ${ }^{\text {bbb }} p<0.001$, bbbb $p<0.0001$, vs. basal; ' $p<0.05$, cc $p<0.01$, cccc $p<0.0001$, vs. CC; ${ }^{*} p<0.05,{ }^{* * *} p<0.001,{ }^{* * * *} p<0.0001$ vs. TC. Statistical analysis was performed by one-way ANOVA with Bonferroni post-hoc test. Results are expressed as boxplots; median with whiskers min to max. p.i. = post impact. medium stimulation of isolated CSPCs significantly enhanced the gene expression of pro-inflammatory but also anti-inflammatory mediators, which was not the case in equivalently treated chondrocytes. Moreover, exposure to trauma-associated factors resulted in a kinetic response including not only accelerated cell proliferation, improved in vitro wound healing capacities and directed migration but also suppressed chondrogenic differentiation. In addition, antioxidative or chondroanabolic therapeutic interventions had diverse influence on the post-traumatic response, depending on whether the therapeutics were applied immediately after trauma or were retrospectively added to the TC medium.

Previous studies describe an augmented percentage of $\mathrm{CD} 105^{+} / 166^{+}$cells (Bosserhoff et al., 2014; Grogan et al., 2009) as well as an increased cell cluster formation by Notch-1-, STRO-1- and VCAM1- expressing cells (Lotz et al., 2010) within an OAaffected tissue. In accordance with these findings, higher incidence of MSC marker-positive cells were found within cartilage explants after ex vivo trauma. This might be related to the enhanced migratory and mitotic activity of TC-medium-stimulated CSPCs, as seen in other studies (Joos et al., 2013; Seol et al., 2012). To investigate the influence of DAMP release on CSPC proliferation separately from the mechanical impact, in future studies, unimpacted cartilage tissue could be exposed to TC medium, followed by flow cytometric analysis. This might also provide information about influences on the CSPC pool of adjacent uninjured tissue as a possible source for local recruitment of chondrogenic cells.

Cartilage trauma results in an immediate cell death associated with the release of endogenous DAMPs, triggering inflammatory and catabolic response of synovial and cartilage cells (Sokolove and Lepus, 2013). With regard to PTOA, intracellular alarmins HMGB1 and S100A8/9 play a crucial role in inflammation and degradative processes (Liu-Bryan R, 2010; Schelbergen et al., 2012). While HMGB1 induces both RAGE and TLR4 signalling (Liu-Bryan $R, 2010), S 100 A 8 / 9$ might primarily function through the interaction with TLR4 (Schelbergen et al., 2012). Exposure of BM-MSCs to DAMPs results in enhanced TLR expression and subsequent transformation of non-immunogenic BM-MSCs into chemotactic immunomodulatory cells, driving the recruitment of immune cells towards the impact site. This process is referred to as TLR-priming (DelaRosa et al., 2012; Najar et al., 2017). Comparable effects on TLR and RAGE gene expression were observed in TCmedium-stimulated CSPCs, indicating that CSPCs could be equally primed due to trauma-associated conditions.

While the release of intracellular DAMPs peaked $24 \mathrm{~h}$ after cartilage trauma and declined afterwards continuously because of decelerated propagation of cell death, ECM-related Fn-fs peak at day 5 (Ding et al., 2014; Wang et al., 2015). 
The delayed appearance can be explained by the protease-dependent hydrolysis of Fn into bioactive Fn-fs, which requires MMP-3 and the fibronectinase ADAM8 (Ding et al., 2014; Zack et al., 2009). Since CSPCs exhibited reduced responsiveness towards TC medium collected $7 \mathrm{~d}$ after trauma, it is tempting to speculate that cell-death-related DAMPs might play a major role in activating CSPCs than proteolytically generated ECM-derived factors, also referred to as matricryptins (Labat-Robert, 2003), do, at least in the present study. Therefore, attenuated responsiveness towards medium from impacted and subsequently treated cartilage explants was hypothesised to rely on cell-protective effects of the therapeutics and consequent prevention of intracellular DAMP release. Although, previous results reveal significant differences in the therapeutic efficacies in terms of initial harm reduction after cartilage, which are particularly pronounced between NAC (strong protection) and IGF-1 (weak protection) (Riegger et al., 2017), the alleviating effect was virtually similar after TIC, TFC, TBC and TNC stimulation. However, decreased responsiveness towards the medium of treated cartilage explants could not be confirmed in the alamarBlue ${ }^{\circledR}$ or chemotaxis assay. This might rely on the immediate trauma-induced mechanical release of ECM-derived components, such as uncleaved Fn (440 kDa) (Ding et al., 2014). Although, native Fn does not trigger catabolic responses (Yasuda and Poole, 2002), it induces directed migration and proliferation of MSCs and subchondral progenitor cells, indicating an involvement in the recruitment of repair cells towards injury sites (Kalkreuth et al., 2014; Thibault et al., 2007).

Retrospective addition of the therapeutics to TC-medium-stimulated CSPCs uncovered substantial difference among the individual effects. While BMP7 consistently attenuated the proinflammatory response of CSPCs, both as immediate and retrospective treatment, the efficacy of the other tested therapeutics was largely limited to immediate treatment. DAMP-induced gene expression of CXCL1 and IL-8 was even enhanced by retrospective application of FGF18 or IGF-1, which might be connected to the expression of $I L-1 \beta$. Comparable increase of IL- 8 and CLCX1, but also IL-1ß, IL-6 and other chemokines, is observed after addition of FGF18 to IL-1ß-stimulated chondrocytes (Sandell et al., 2008). Ding et al. (2017) demonstrate a synergistic interaction between HMGB1 and IL-1B and conclude that pro-catabolic effects of certain DAMPs might rely on the co-existence of cytokines or Fn-fs. Indeed, S100A8/9- and HMGB1-induced expression of catabolic enzymes as well as pro- and anti-inflammatory mediators is more pronounced in tissue or isolated cells obtained from OA patients as compared to non-arthritic samples (Dave et al., 2017; Ding et al., 2017; Schelbergen et al., 2012). Similar synergistic effects can be observed in mechanically injured cartilage additionally stimulated with cytokines (Patwari et al., 2003). However, it remains unclear which DAMPs finally led to the adverse interaction with the retrospectively added growth factors and how this was prevented by immediate application. Overall, the identification of the key factors that play a pivotal role in triggering distinct CSPC responses after cartilage trauma clearly deserves further investigation, including unbiased screening approaches (e.g. proteomic profiling).

Despite simultaneous expression of antiinflammatory mediators, pro-inflammatory response of TC-stimulated CSPCs might give rise to concerns, in particular with regard to the pleiotropic IL-6, whose role in OA is not clarified (Tsuchida et al., 2012). However, intra-articular injection of autologous MSCs results in pain relief and decreased joint damage in patients suffering from knee OA, despite - or perhaps precisely because of - the secretion of IL-6 (Lamo-Espinosa et al., 2016; Scheller et al., 2011). Tsuchida et al. (2012) hypothesis is that synovial IL-6 levels might be enhanced in the course of intrinsic regeneration after injury. In alignment with that, binding to its soluble receptor (sIL-6R) and subsequent activation of the IL-6/STAT-3 pathway is essential for the chondrogenic differentiation of MSCs (Kondo et al., 2015), whereas the absence of sIL-6R results in opposite effect and maintenance of stem cell characteristics, such as enhanced proliferation and wound healing (Pricola et al., 2009). Interestingly, IL-6 co-localises with CD166 ${ }^{+}$cells in human cartilage (presumably CSPCs) (Kondo et al., 2015). In line with that, a possible link between enhanced percentage of $\mathrm{CD}_{166^{+}}$cells within impacted cartilage explants, increased IL- 6 expression and reduced chondrogenic differentiation in the presence of FGF18 was found in the present study. Whether and to what degree CSPC-derived IL-6 might impact the chondrogenic phenotype of adjacent chondrocytes or contribute to synovitis and immune cell recruitment was not addressed.

IL-1ß and HMGB1 are associated with cytokine release and osteogenic differentiation of MSCs (Feng et al., 2016; Ousema et al., 2012). Moreover, HMGB1 is actively secreted by hypertrophic chondrocytes during endochondral ossification (Taniguchi et al., 2007). In this context, IL-8 and CXCL1 promote chondrocyte hypertrophy as a sign of terminal differentiation as well as pathologic calcification during OA (Merz et al., 2003). Accordingly, enhanced gene expression levels of $I L-1 \beta, I L-8$ and $C X C L 1$ and suppression of chondrogenic differentiation in TCmedium-stimulated CSPCs were observed in the present study, with all these effect reduced by BMP7.

Apart from TC-medium-stimulation, chondrogenic differentiation of CSPCs was also suppressed by NAC and FGF18. FGF18 is an essential regulator during the embryonic development of the skeletal system, although, it enhances cell proliferation and differentiation in osteogenesis while having opposite effects in chondrogenesis (Ohbayashi et al., 2002; Shu 
et al., 2016). Accordingly, FGF18-stimulation of CSPCs resulted in enhanced expression levels of $I L-8$ and CLCX1 and enhanced expression of MMP-13 and type $X$ collagen - hypertrophic markers commonly upregulated during IL8/CXCL-1 driven calcification (Merz et al., 2003) - in unimpacted cartilage explants exposed to FGF18 (Riegger et al., 2017). Gigout et al. (2017) report chondroanabolic properties of sprifermin (FGF18) by an intermittent regimen in which $100 \mathrm{ng} / \mathrm{mL}$ sprifermin is applied for only 1 week or $1 \mathrm{~d}$ per week ( 3 times) over a 4 -week culture period in serum-containing medium. In line with the results of the current study, permanent application suppressed chondroanabolic characteristics of 3D-cultured chondrocytes.

NAC-mediated interference of chondrogenic differentiation, which even diminished simultaneous stimulation with IGF-1 or BMP7, was largely dependent on the exposure time point. Addition of NAC during the first week might have stronger impairing effect as compared to its application during the second week (Fig. 3f). Chondrogenesis proceeds in several stages (Chen et al., 2009), including cellular condensation, ECM remodelling and matrix construction, regulated by various autocrine and paracrine mediators as well as cell-cell/cell-matrix interaction (Li and Dong, 2016). Proliferation (Dexheimer et al., 2012), ROS accumulation and expression of MMPs play a crucial role during the early phases of chondrogenic differentiation (Kim et al., 2010). Since NAC is an efficient ROS scavenger and inhibitor of proliferation, MMP expression and proteolytic activity (Riegger et al., 2016), it was concluded that these properties interfere with the chondrogenic differentiation. Nevertheless, withdrawal of NAC after $7 \mathrm{~d}$ allowed resumption of the chondrogenic differentiation that was significantly improved by subsequent stimulation with IGF-1 or BMP7.

The findings about the post-traumatic response of CSPCs not only affirmed a contribution to regenerative processes but also provided first evidence for immunomodulatory properties after cartilage injury. Since it was quite ambitious to target the functional role of this small ECM-embedded subpopulation in its natural environment, most of the study objectives were elucidated in isolated CSPCs. Therefore, future studies on the regenerative potentials of CSPCs should be extended to the crosstalk with synovial cells, chondrocytes and cartilage explants.

\section{Conclusions}

The present results indicated that CSPCs responded to cartilage injury and the correspondingly released DAMPs by enhanced proliferation, migration and expression of immunomodulatory mediators. Despite increased early wound healing capacities, the chondrogenic differentiation was impaired by trauma-associated factors, indicating a counteraction in the regeneration of cartilage defects. Although, the prevailing effector molecules were not identified, it could be demonstrated that the post-traumatic behaviour of CSPCs could be differentially modified by pharmacologic intervention, whereby BMP7 revealed the most beneficial effects. Overall, prevention of DAMP release or inhibition of respective pattern recognition receptors might represent a promising therapeutic target not only to circumvent its detrimental effects and possible contribution in the subsequent development of PTOA (Rosenberg et al., 2017) but also to improve regenerative processes by CSPCs.

\section{Acknowledgements}

This work was partly supported by a research grant from the German Ministry of Defence (E/U2A/ CD524/DF560). We thank Mrs. Christiane Schulz for technical assistance with the preparation of the histological analysis and safranin-O staining of the chondrogenic differentiation. Further, we would like to thank Prof. Dr Heiko Reichel (Department of Orthopaedics, University of Ulm, Germany) for providing the study material.

\section{References}

Bertheloot D, Latz E (2017) HMGB1, IL-1alpha, IL-33 and S100 proteins: dual-function alarmins. Cell Mol Immunol 14: 43-64.

Bosserhoff AK, Hofmeister S, Ruedel A, Schubert T (2014) DCC is expressed in a CD166positive subpopulation of chondrocytes in human osteoarthritic cartilage and modulates CRE activity. Int J Clin Exp Pathol 7: 1947-1956.

Chen WH, Lai MT, Wu AT, Wu CC, Gelovani JG, Lin CT, Hung SC, Chiu WT, Deng WP (2009) In vitro stage-specific chondrogenesis of mesenchymal stem cells committed to chondrocytes. Arthritis Rheum 60: 450-459.

Dave M, Islam AB and Amin AR (2017) The b-box of HMGB1 amplifies nitric oxide production in human osteoarthritis-affected cartilage. Am J Arthrits Res 1: 1-4.

DelaRosa O, Dalemans W, Lombardo E (2012) Toll-like receptors as modulators of mesenchymal stem cells. Front Immunol 3: 182. DOI: 10.3389/ fimmu.2012.00182.

Dexheimer V, FrankS, RichterW (2012) Proliferation as a requirement for in vitro chondrogenesis of human mesenchymal stem cells. Stem Cells Dev 21: 21602169.

Diaz-Romero J, Gaillard JP, Grogan SP, Nesic D, Trub T, Mainil-Varlet P (2005) Immunophenotypic 
analysis of human articular chondrocytes: changes in surface markers associated with cell expansion in monolayer culture. J Cell Physiol 202: 731-742.

Ding L, Buckwalter JA, Martin JA (2017) DAMPs synergize with cytokines or fibronectin fragment on inducing chondrolysis but lose effect when acting alone. Mediators Inflamm 2017: 2642549.

Ding L, Guo D, Homandberg GA, Buckwalter JA, Martin JA (2014) A single blunt impact on cartilage promotes fibronectin fragmentation and upregulates cartilage degrading stromelysin-1/ matrix metalloproteinase-3 in a bovine ex vivo model. J Orthop Res 32: 811-818.

Dominici M, Le Blanc K, Mueller I, SlaperCortenbach I, Marini FC, Krause DS, Deans RJ, Keating A, Prockop DJ, Horwitz EM (2006) Minimal criteria for defining multipotent mesenchymal stromal cells. The International Society for Cellular Therapy position statement. Cytotherapy 8: 315-317.

Elsaesser AF, Schwarz S, Joos H, Koerber L, Brenner RE, Rotter N (2016) Characterization of a migrative subpopulation of adult human nasoseptal chondrocytes with progenitor cell features and their potential for in vivo cartilage regeneration strategies. Cell Biosci 6: 11. DOI: 10.1186/s13578-016-0078-6.

Feng L, Xue DT, Chen EM, Zhang W, Gao X, Yu JW, Feng YD, Pan ZJ (2016) HMGB1 promotes the secretion of multiple cytokines and potentiates the osteogenic differentiation of mesenchymal stem cells through the Ras/MAPK signaling pathway. Exp Ther Med 12: 3941-3947.

Fiedler J, Brill C, Blum WF, Brenner RE (2006) IGF-I and IGF-II stimulate directed cell migration of bone-marrow-derived human mesenchymal progenitor cells. Biochem Biophys Res Commun 345: 1177-1183.

Flannery CR, Zollner R, Corcoran C, Jones AR, Root A, Rivera-Bermudez MA, Blanchet T, Gleghorn JP, Bonassar LJ, Bendele AM, Morris EA, Glasson SS (2009) Prevention of cartilage degeneration in a rat model of osteoarthritis by intraarticular treatment with recombinant lubricin. Arthritis Rheum 60: 840847.

Gigout A, Guehring H, Froemel D, Meurer A, Ladel C, Reker D, Bay-Jensen AC, Karsdal MA, Lindemann S (2017) Sprifermin (rhFGF18) enables proliferation of chondrocytes producing a hyaline cartilage matrix. Osteoarthritis Cartilage 25: 18581867.

Grogan SP, Barbero A, Winkelmann V, Rieser F, Fitzsimmons JS, O’Driscoll S, Martin I, Mainil-Varlet P (2006) Visual histological grading system for the evaluation of in vitro-generated neocartilage. Tissue Eng 12: 2141-2149.

Grogan SP, Miyaki S, Asahara H, D’Lima DD, Lotz MK (2009) Mesenchymal progenitor cell markers in human articular cartilage: normal distribution and changes in osteoarthritis. Arthritis Res Ther 11: R85.

Henrotin Y, Kurz B, Aigner T (2005) Oxygen and reactive oxygen species in cartilage degradation: friends or foes? Osteoarthritis Cartilage 13: 643-654.
Jiang Y, Tuan RS (2015) Origin and function of cartilage stem/progenitor cells in osteoarthritis. Nat Rev Rheumatol 11: 206-212.

Jonkman JEN, Cathcart JA, Xu F, Bartolini ME, Amon JE, Stevens KM, Colarusso P (2014) An introduction to the wound healing assay using livecell microscopy. Cell Adh Migr 8: 440-451.

Joos H, Wildner A, Hogrefe C, Reichel H, Brenner RE (2013) Interleukin-1 beta and tumor necrosis factor alpha inhibit migration activity of chondrogenic progenitor cells from non-fibrillated osteoarthritic cartilage. Arthritis Res Ther 15: R119.

Kalkreuth RH, Kruger JP, Lau S, Niemeyer P, Endres M, Kreuz PC, Kaps C (2014) Fibronectin stimulates migration and proliferation, but not chondrogenic differentiation of human subchondral progenitor cells. Regen Med 9: 759-773.

Kim KS, Choi HW, Yoon HE, Kim IY (2010) Reactive oxygen species generated by NADPH oxidase 2 and 4 are required for chondrogenic differentiation. J Biol Chem 285: 40294-40302.

Kleemann RU, Krocker D, Cedraro A, Tuischer J, Duda GN (2005) Altered cartilage mechanics and histology in knee osteoarthritis: relation to clinical assessment (ICRS Grade). Osteoarthritis Cartilage 13: 958-963.

Koelling S, Kruegel J, Irmer M, Path JR, Sadowski B, Miro X, Miosge N (2009) Migratory chondrogenic progenitor cells from repair tissue during the later stages of human osteoarthritis. Cell Stem Cell 4: 324335.

Kondo M, Yamaoka K, Sakata K, Sonomoto K, Lin L, Nakano K, Tanaka Y (2015) Contribution of the interleukin-6/STAT-3 signaling pathway to chondrogenic differentiation of human mesenchymal stem cells. Arthritis Rheum 67: 1250-1260.

Labat-Robert J (2003) Age-dependent remodeling of connective tissue: role of fibronectin and laminin. Pathol Biol 51: 563-568.

Lamo-Espinosa JM, Mora G, Blanco JF, GraneroMolto F, Nunez-Cordoba JM, Sanchez-Echenique C, Bondia JM, Aquerreta JD, Andreu EJ, Ornilla E, Villaron EM, Valenti-Azcarate A, Sanchez-Guijo F, del Canizo MC, Valenti-Nin JR, Prosper F (2016) Intra-articular injection of two different doses of autologous bone marrow mesenchymal stem cells versus hyaluronic acid in the treatment of knee osteoarthritis: multicenter randomized controlled clinical trial (phase I/II). J Transl Med 14: 246.

Li JM, Dong SW (2016) The signaling pathways involved in chondrocyte differentiation and hypertrophic differentiation. Stem Cells International 2014. DOI: $10.1155 / 2016 / 2470351$.

Liu-Bryan R TR (2010) Chondrocyte innate immune MyD88-dependent signaling drives procatabolic effects of the endogenous TLR2/TLR4 ligands LMW-HA and HMGB1. Arthritis Rheum 62: 2004-2012.

Lotz MK, Otsuki S, Grogan SP, Sah R, Terkeltaub R, D'Lima D (2010) Cartilage cell clusters. Arthritis Rheum 62: 2206-2218. 
Merz D, Liu R, Johnson K, Terkeltaub R (2003) IL-8/ CXCL8 and growth-related oncogene alpha/CXCL1 induce chondrocyte hypertrophic differentiation. J Immunol 171: 4406-4415.

Najar M, Krayem M, Meuleman N, Bron D, Lagneaux L (2017) Mesenchymal stromal cells and Toll-like receptor priming: a critical review. Immune Netw 17: 89-102.

Ohbayashi N, Shibayama M, Kurotaki Y, Imanishi M, Fujimori T, Itoh N, Takada S (2002) FGF18 is required for normal cell proliferation and differentiation during osteogenesis and chondrogenesis. Genes Dev 16: 870-879.

Ousema PH, Moutos FT, Estes BT, Caplan AI, Lennon DP, Guilak F, Weinberg JB (2012) The inhibition by interleukin 1 of MSC chondrogenesis and the development of biomechanical properties in biomimetic 3D woven PCL scaffolds. Biomaterials 33: 8967-8974.

Patwari P, Cook MN, DiMicco MA, Blake SM, James IE, Kumar S, Cole AA, Lark MW, Grodzinsky AJ (2003) Proteoglycan degradation after injurious compression of bovine and human articular cartilage in vitro: interaction with exogenous cytokines. Arthritis Rheum 48: 1292-1301.

Pricola KL, Kuhn NZ, Haleem-Smith H, Song YJ, Tuan RS (2009) Interleukin-6 maintains bone marrow-derived mesenchymal stem cell stemness by an ERK1/2-dependent mechanism. J Cell Biochem 108: $577-588$.

Riegger J, Joos H, Palm HG, Friemert B, Reichel H, Ignatius A, Brenner RE (2016) Antioxidative therapy in an ex vivo human cartilage traumamodel: attenuation of trauma-induced cell loss and ECM-destructive enzymes by $\mathrm{N}$-acetyl cysteine. Osteoarthritis Cartilage 24: 2171-2180.

Riegger J, Joos H, Palm HG, Friemert B, Reichel H, Ignatius A, Brenner RE (2017) Striking a new path in reducing cartilage breakdown: combination of antioxidative therapy and chondroanabolic stimulation after blunt cartilage trauma. J Cell Mol Med 22: 77-88.

Rosenberg JH, Rai V, Dilisio MF, Agrawal DK (2017) Damage-associated molecular patterns in the pathogenesis of osteoarthritis: potentially novel therapeutic targets. Mol Cell Biochem 434: 171-179.

Sandell LJ, Xing X, Franz C, Davies S, Chang LW, Patra D (2008) Exuberant expression of chemokine genes by adult human articular chondrocytes in response to IL-1beta. Osteoarthritis Cartilage 16: 1560-1571.

Schelbergen RFP, Blom AB, van den Bosch MHJ, Sloetjes A, Abdollahi-Roodsaz S, Schreurs BW, Mort JS, Vogl T, Roth J, van den Berg WB, van Lent PLEM (2012) Alarmins S100A8 and S100A9 elicit a catabolic effect in human osteoarthritic chondrocytes that is dependent on toll-like receptor 4 . Arthritis Rheum 64: 1477-1487.

Scheller J, Chalaris A, Schmidt-Arras D, Rose-John $S$ (2011) The pro- and anti-inflammatory properties of the cytokine interleukin-6. Biochim Biophys Acta 1813: $878-888$.

Seol D, McCabe DJ, Choe H, Zheng H, Yu Y, Jang K, Walter MW, Lehman AD, Ding L, Buckwalter JA, Martin JA (2012) Chondrogenic progenitor cells respond to cartilage injury. Arthritis Rheum 64: 36263637.

Shu C, Smith SM, Little CB, Melrose J (2016) Use of FGF-2 and FGF-18 to direct bone marrow stromal stem cells to chondrogenic and osteogenic lineages. Future Sci OA 2: FSO142.

Sokolove J, Lepus CM (2013) Role of inflammation in the pathogenesis of osteoarthritis: latest findings and interpretations. Ther Adv Musculoskelet Dis 5: 77-94.

Sui Y, Lee JH, DiMicco MA, Vanderploeg EJ, Blake SM, Hung HH, Plaas AH, James IE, Song XY, Lark MW, Grodzinsky AJ (2009) Mechanical injury potentiates proteoglycan catabolism induced by interleukin-6 with soluble interleukin-6 receptor and tumor necrosis factor alpha in immature bovine and adult human articular cartilage. Arthritis Rheum 60: 2985-2996.

Taniguchi N, Yoshida K, Ito T, Tsuda M, Mishima Y, Furumatsu T, Ronfani L, Abeyama K, Kawahara K, Komiya S, Maruyama I, Lotz M, Bianchi ME, Asahara H (2007) Stage-specific secretion of HMGB1 in cartilage regulates endochondral ossification. Mol Cell Biol 27: 5650-5663.

Thibault MM, Hoemann CD, Buschmann MD (2007) Fibronectin, vitronectin, and collagen I induce chemotaxis and haptotaxis of human and rabbit mesenchymal stem cells in a standardized transmembrane assay. Stem Cell Dev 16: 489-502.

Tsuchida AI, Beekhuizen M, Rutgers M, van Osch GJVM, Bekkers JEJ, Bot AGJ, Geurts B, Dhert WJA, Saris DBF, Creemers LB (2012) Interleukin-6 is elevated in synovial fluid of patients with focal cartilage defects and stimulates cartilage matrix production in an in vitro regeneration model. Arthritis Res Ther 14: R262.

van Buul GM, Villafuertes E, Bos PK, Waarsing JH, Kops N, Narcisi R, Weinans H, Verhaar JAN, Bernsen MR, van Osch GJVM (2012) Mesenchymal stem cells secrete factors that inhibit inflammatory processes in short-term osteoarthritic synovium and cartilage explant culture. Osteoarthritis Cartilage 20: 1186-1196.

Wang X, Brouillette MJ, Ayati BP, Martin JA (2015) A validated model of the pro- and anti-inflammatory cytokine balancing act in articular cartilage lesion formation. Front Bioeng Biotechnol 3: 25.

Whittaker JL, Woodhouse LJ, Nettel-Aguirre A, Emery CA (2015) Outcomes associated with early post-traumatic osteoarthritis and other negative health consequences 3-10 years following knee joint injury in youth sport. Osteoarthritis Cartilage 23: 1122-1129.

Xue K, Zhang X, Qi L, Zhou J, Liu K (2016) Isolation, identification, and comparison of cartilage 
stem progenitor/cells from auricular cartilage and perichondrium. Am J Transl Res 8: 732-741.

Yasuda T, Poole AR (2002) A fibronectin fragment induces type II collagen degradation by collagenase through an interleukin-1-mediated pathway. Arthritis Rheum 46: 138-148.

Yu Y, Brouillette MJ, Seol D, Zheng HJ, Buckwalter JA, Martin JA (2015) Use of recombinant human stromal cell-derived factor 1 alpha-loaded fibrin/ hyaluronic acid hydrogel networks to achieve functional repair of full-thickness bovine articular cartilage via homing of chondrogenic progenitor cells. Arthritis Rheum 67: 1274-1285.

Zack MD, Malfait AM, Skepner AP, Yates MP, Griggs DW, Hall T, Hills RL, Alston JT, Nemirovskiy OV, Radabaugh MR, Leone JW, Arner EC, Tortorella MD (2009) ADAM-8 isolated from human osteoarthritic chondrocytes cleaves fibronectin at Ala(271). Arthritis Rheum 60: 27042713.

Zhou C, Zheng H, Buckwalter JA, Martin JA (2016) Enhanced phagocytic capacity endows chondrogenic progenitor cells with a novel scavenger function within injured cartilage. Osteoarthritis Cartilage 24: 1648-1655.

Zhou C, Zheng HJ, Seol DR, Yu Y, Martin JA (2014) Gene expression profiles reveal that chondrogenic progenitor cells and synovial cells are closely related. J Orthop Res 32: 981-988.

\section{Discussion with Reviewers}

Andrea Barbero: The authors studied the posttraumatic behaviour of chondro-progenitor cells isolated from cartilage specimens from $\mathrm{AO}$ knee (i.e. an environment in which inflammatory and degrading factors are highly expressed). Healthy and OA cartilage cells (even if collected from "macroscopically intact" regions) substantially differ in their responses to environmental stimuli (mechanical and biochemical). Therefore, it is highly possible that the reported results were specific to $\mathrm{OA}$ cells and cannot be extended to chondrocytes from non-OA joints. What are the author's thoughts about the relevance of their findings for the treatment of acute post-traumatic arthritis?

Authors: The authors are aware of the issue regarding the pathologic history of the used specimen and the possible influence on the results. However, while human articular cartilage from non-OA-joints is hardly available, considering necessary ethical guidelines, the usage of animal material might result in species-related differences (Pedersen et al., 2013, additional reference). With respect to translational relevance, the use of human macroscopically intact articular cartilage and CSPCs from patients with OA most closely addresses the role of blunt trauma for progression of the disease at an early stage. Whether cells from healthy cartilage of younger persons would react in a similar way remains an open question. Despite potential differences between CSPCs from macroscopically intact OA and non-OA cartilage, it is the authors' opinion that the results provide an important insight into the post-traumatic response of this cell population and the possibility of modifying its response by therapeutic intervention in the respective experimental setting. Although, it is only possible to speculate on the actual relevance of this knowledge for future treatment strategies at this time, the present results might suggest novel therapeutic approaches for reducing the risk of developing posttraumatic osteoarthritis.

Qian Chen: The role of IL-6 in cartilage progenitor cells is very interesting. Will the authors further study whether IL-6 is beneficial or detrimental (or maybe both) to cartilage repair due to progenitor cells?

Authors: The role of IL-6 is controversially debated without reaching an agreement (Tsuchida et al., 2012). Its pleiotropic effects might result from various, presently unknown, determinants that need to be clarified in future studies. Therefore, it would be interesting to investigate in detail some additional aspects, for instance the extrinsic addition of IL-6 with and without sIL-6R as well as selective inhibition experiments, in the present cartilage-trauma model. Further, it would be interesting to study how the CSPC-derived cocktail of immunomodulatory mediators as a whole affect the cartilage homeostasis.

Qian Chen: In addition to experiments with conditioned medium, what else can be done to test the DAMPs role in this process?

Authors: Additional unbiased approaches might help to identify the predominant factors driving the post-traumatic response. Potential candidates, which are tested in some instances, are listed in the study by Stevens et al. (2008, additional reference) and in the reviews by Sokolove and Lepus (2013) and Schäfer (2014, additional reference), which provide a comprehensive overview about DAMPs. Further investigation on the functional role of DAMPs released after cartilage trauma might include stimulation of isolated cartilage cells/cartilage explants with the individual factors (Ding et al., 2017), specific scavenging of target molecules or inhibition of DAMPs/pattern recognition receptors (Happonen et al., 2012, additional reference; Rosenberg, 2017).

\section{Additional References}

Happonen KE, Heinegard D, Saxne T, Blom AM (2012) Interactions of the complement system with molecules of extracellular matrix: relevance for joint diseases. Immunobiology 217: 1088-1096.

Pedersen DR, Goetz JE, Kurriger GL, Martin JA (2013) Comparative digital cartilage histology for 
human and common osteoarthritis models. Orthop Res Rev 2013: 13-20.

Schäfer L (2014) Complexity of danger: the diverse nature of damage-associated molecular patterns. J Biol Chem 289: 35237-35245.

Stevens AL, Wishnok JS, Chai DH, Grodzinsky AJ, Tannenbaum SR (2008) A sodium dodecyl sulfate-polyacrylamide gel electrophoresis-liquid chromatography tandem mass spectrometry analysis of bovine cartilage tissue response to mechanical compression injury and the inflammatory cytokines tumor necrosis factor alpha and interleukin-1beta. Arthritis Rheum 58: 489-500.

Editor's note: The Scientific Editor responsible for this paper was Brian Johnstone. 